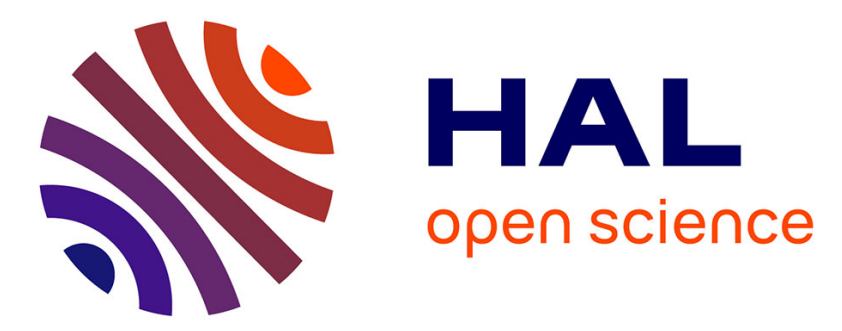

\title{
On the validity of neutral gas temperature by emission spectroscopy in micro-discharges close to atmospheric pressure
}

Sylvain Iséni, Ronan Michaud, Philippe Lefaucheux, Goran Sretenović, Volker Schulz-von Der Gathen, Remi Dussart

\section{To cite this version:}

Sylvain Iséni, Ronan Michaud, Philippe Lefaucheux, Goran Sretenović, Volker Schulz-von Der Gathen, et al.. On the validity of neutral gas temperature by emission spectroscopy in micro-discharges close to atmospheric pressure. Plasma Sources Science and Technology, 2019, 28 (6), pp.065003. 10.1088/1361-6595/ab1dfb . hal-02117169

\section{HAL Id: hal-02117169 \\ https://hal.science/hal-02117169}

Submitted on 14 Jul 2019

HAL is a multi-disciplinary open access archive for the deposit and dissemination of scientific research documents, whether they are published or not. The documents may come from teaching and research institutions in France or abroad, or from public or private research centers.
L'archive ouverte pluridisciplinaire HAL, est destinée au dépôt et à la diffusion de documents scientifiques de niveau recherche, publiés ou non, émanant des établissements d'enseignement et de recherche français ou étrangers, des laboratoires publics ou privés. 


\title{
On the validity of neutral gas temperature by emission spectroscopy in micro-discharges close to atmospheric pressure
}

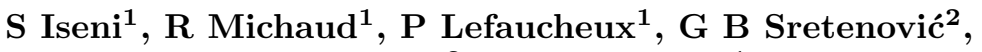 \\ V Schulz-von der Gathen ${ }^{3}$ and R Dussart ${ }^{1}$ \\ ${ }^{1}$ GREMI-(Groupe de Recherches sur l'Énergétique des Milieux Ionisés) - UMR \\ 7344 Université d'Orléans/CNRS, France. \\ ${ }^{2}$ Faculty of Physics, University of Belgrade, Serbia. \\ ${ }^{3}$ Chair of Experimental Physics II, Ruhr-Universität Bochum, Germany. \\ E-mail: sylvain.iseni@univ-orleans.fr
}

\begin{abstract}
The neutral gas temperature $\left(T_{\mathrm{g}}\right)$ of a single micro-hollow cathode discharge (MHCD) elaborated on silicon wafer is investigated. The MHCD is continuously powered in DC yielding a plasma in $\mathrm{He}$, $\mathrm{Ar}$ and $\mathrm{N}_{2}$ gases close to atmospheric pressure. Values of $T_{\mathrm{g}}$ determined by means of optical emission spectroscopy inside and in the vicinity of a single cavity of $100 \mu \mathrm{m}$ diameter. In this work, the use of the resonant broadening to infer $T_{\mathrm{g}}$ is thoroughly reconsidered taking into account the reevaluation of an empirical coefficient as well as including the weaker contribution of the Van der Waals interaction in the line profile analysis. $T_{\mathrm{g}}$ is found to be around $360 \mathrm{~K}$ in He while in Ar it ranges from $460 \mathrm{~K}$ to $860 \mathrm{~K}$ depending on the current. A temperature gradient is observed between the cavity and the surrounding gas, which is correlated with the design of the MHCD reactor.

A second approach involves the study of the relative rotational population distributions of several $\mathrm{N}_{2}(\mathrm{C}-\mathrm{B})$ vibrational bands to infer the rotational temperature $\left(T_{\text {rot }}\right)$. While the latter is commonly assumed to approximated $T_{\mathrm{g}}$, its validity will be discussed based on experimental results. Discrepancies between $T_{\text {rot }}$ from different vibrational bands as well as with values found with the resonant broadening are investigated using different operating regimes of the MHCD. The validity of both approaches will be discussed supported by a comprehensive evaluation of the $T_{\mathrm{g}}$ and $T_{\text {rot }}$ uncertainty estimations. The analysis of resonant atomic line profile appears to be a reliable and accurate method to measure $T_{\mathrm{g}}$ in absolute room temperature atmospheric pressure plasma sources used in industrial processes as well as in environmental and biomedical applications.

doi:10.1088/1361-6595/ab1dfb
\end{abstract}

Submitted to: Plasma Sources Sci. Technol. 


\section{Introduction}

Room temperature atmospheric pressure plasma sources in essence belong to the category of micro-plasmas with at least one of their dimension in the micrometer scale [1]. Depending on the timescale of the electric excitation, the gas and the design of the source, the plasma is either diffused or filamentary, transient or continuous. Micro-hollow cathode discharge (MHCD) are plasma sources with all their dimensions ranging in the micro-meter scale. The concept of MHCD was introduced in the middle of the 90's and has been extensively investigated over the last two decades $[2,3]$. This plasma source benefits from multiple advantages such as avoiding cost intensive vacuum techniques, the compactness, the integration ease to adapt to existing systems and the relatively low neutral gas temperature. To this, one can add the high adjustability of the source to produce a localized plasma in the micrometer size on a time scale ranging from tens of nanoseconds to continuous time. This tunability is in favor of scaling multiple plasma parameters related to the non-equilibrium plasma chemistry and the emission of energetic radiations used to treat surfaces or gas volumes. As a real asset, MHCD reactor can be combined to form large arrays of microplasma allowing to adapt the source to scalable workflows. The innovative potential of MHCD reactors has led to the development of the first uniform closed-packed arrays of micro-plasma jets propagating into a volume of atmospheric air [4]. Later the concept was extended to typical capillary plasma jet geometries [5] generating guided ionization waves [6] -or guided streamers [7]- to produce multi-jet plasmas from a dielectric capillary, originally named for plasma thorn [8]. Consequently, a large amount of applications are taking advantage of MHCD properties. For instance in the field of biomedical applications, surface activation, pollutant degradation or reforming, lighting, reactive oxygen and nitrogen species productions [9].

The determination of the gas temperature is of crucial interest to compute reaction rates of the plasma kinetic chemistry but also to choose and structure the materials used to realize the MHCD. Furthermore, solid knowledge of the neutral gas temperature supports the intention to better understand fundamental processes governing the plasma mechanisms as well as optimizing the source to the targeted applications. The accurate and reliable measurements of the neutral gas temperature can be a real challenge while the temperature values are close to the ambient. Last but not least, thermal effects are often involved in plasma diagnostics, which means that knowing the neutral gas temperature is to some extent necessary to interpret raw data having a thermal dependence (i.e. determination of chemical species concentration). Due to the microscopic size, optical spectroscopy is a method of choice to diagnose the discharge. Investigations of the neutral gas temperature in MHCDs have already been studied involving different approaches. For instance this has been realized through the analysis of ro-vibrational bands of molecules of $\mathrm{N}_{2}[10,11,12,13], \mathrm{N}_{2}{ }^{+}$[14] and $\mathrm{OH}$ [15]. One reports on MHCDs gas temperature by studying the profile of an atomic transition obtained by optical emission spectroscopy [15] or by laser absorption spectroscopy [16].

In this study, one focuses on the characterization of the neutral gas temperature in a single MHCD reactor supplied with DC excitation in $\mathrm{He}, \mathrm{Ar}$ and $\mathrm{N}_{2}$ gases close to atmospheric pressure. Taking advantage of MEMS fabrication technologies, MHCD reactors can be manufactured with significantly reduced electrode gap allowing for lowering the breakdown voltage. Starting from a silicon wafer, the micro-cavity is shaped by successive operations involving well controlled processes developed in 
microelectronics. The study of the gas temperature is carried out by means of space resolved optical emission spectroscopy. Two experimental ways are investigated depending on the gas mixture $\left(\mathrm{He}, \mathrm{Ar}\right.$ and $\left.\mathrm{N}_{2}\right)$. As a first approach, the profile of resonant atomic lines taking into account the Van der Waals broadening is thoroughly analyzed to infer the gas temperature. For instance, the use of collisional line broadening was extensively studied in surfatron (microwave plasma source) where resonant, Van der Waals and Doppler contributions are investigated due to the relatively high gas temperature $[17,18]$. While the broadening of resonant lines is particularly pronounced in room temperature atmospheric pressure plasmas, their study to measure the neutral gas temperature is often ignored. A complementary approach based on the determination of the $\mathrm{N}_{2}(\mathrm{C}-\mathrm{B})$ band rotational temperature is considered for pure $\mathrm{N}_{2}$ and He discharges. To properly exploit information from emission spectroscopy, particular attention will be paid to to estimate and discuss the uncertainties introduced by the complex formalisms involving tangled spectroscopic constants and to determine the reproducibility of the observations. The validity and limits of each diagnostic methods will be discussed based on the experimental results. Subsequently, temperature values will be measured within the cavity and at the vicinity of the opening, near the outer electrode. A comparison of the thermal properties of the MHCD will be presented and discussed depending on the electrical parameters and the nature of the gas.

\section{Experimental setup}

This section is divided in two parts: the plasma source and the diagnostics implemented around the MHCD to monitor and to measure the electrical properties of the discharge. The optical emission of the plasma is also collected and analyzed.

\subsection{Silicon based $M H C D$ reactor}

The micro-cavity reactors based on silicon wafer are manufactured in the laboratory by means of MEMS fabrication techniques. Such technologies offer the advantage of designing versatile, accurate and reproducible micro structures in terms of geometry and material. The design of the MHCD used in this work has been introduced in a prior work [19] and consists of an axisymmetric isotropic cavity etched in a $\mathrm{Si}$ wafer of typically $500 \mu \mathrm{m}$ thick. Figure 1 shows a schematic of the micro-cavity reactor.

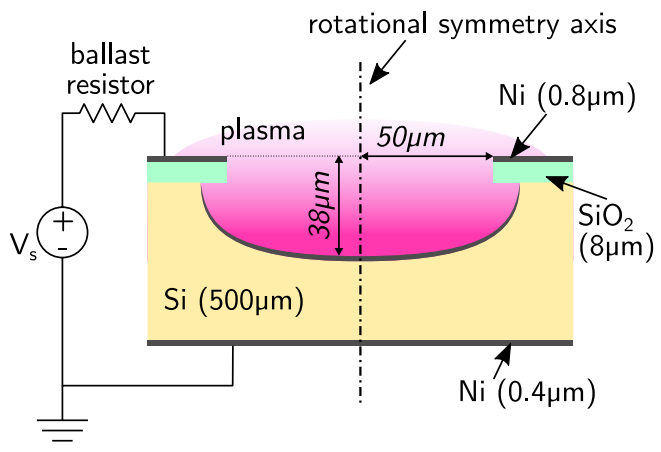

Figure 1. Schematic of a single silicon based MHCD reactor produced by MEMS manufacturing technology. 
The latter has a circular opening diameter of $100 \mu \mathrm{m}$ and a depth of $30 \mu \mathrm{m}$. The Si cavity is electrically isolated by a thin layer of $8 \mu \mathrm{m}$ of silicon dioxide $\left(\mathrm{SiO}_{2}\right)$ formed by thermal oxidation on the wafer surface. The $\mathrm{SiO}_{2}$ is - partly- covered with a thin layer of nickel $(\mathrm{Ni})$ to act as an electrode. The electrode pattern around the cavity opening is defined with lithography techniques before the plasma vapor deposition (PVD) process.

Newly introduced in $[20,19]$, a metallic layer covers the inner surface of the isotropic cavity giving the advantage of a better electrical conductivity of the plasma material interface while protecting the Si surface from ion bombardment, strong implantation and a potential oxidation of $\mathrm{Si}$. The second electrode consists of a metal layer (typically $\mathrm{Ni}$ ) formed at the back of the wafer by a PVD process. A ballast resistor ranging from $30 \mathrm{k} \Omega$ to $1 \mathrm{M} \Omega$ is connected in series to the MHCD reactor and is supplied by a stabilized DC generator (Heinzinger PNC $1500100 \mathrm{ump}$ ).

In operation, the MHCD is placed within a controlled chamber pumped to a pressure below $10^{-5}$ mbar. Then, the volume is filled up with high purity $\mathrm{Ar}$, He or $\mathrm{N}_{2}$ (Alphagaz 2, Air Liquide). A capacitive pressure gauge is used to accurately set the discharge conditions to a static gas pressure. Considering the present design of the MHCD reactor shown in figure 1 and depending on the gas and the pressure, typical voltage and current values used to operate the discharge range from $150 \mathrm{~V}$ to $350 \mathrm{~V}$ and from $4 \mu \mathrm{A}$ to $650 \mu \mathrm{A}$ respectively.

\subsection{Plasma diagnostics}

To diagnose the discharge, electrical and optical measurements are performed simultaneously as shown in figure 2. To measure the discharge voltage ( $\left.V_{\mathrm{MHCD}}\right)$

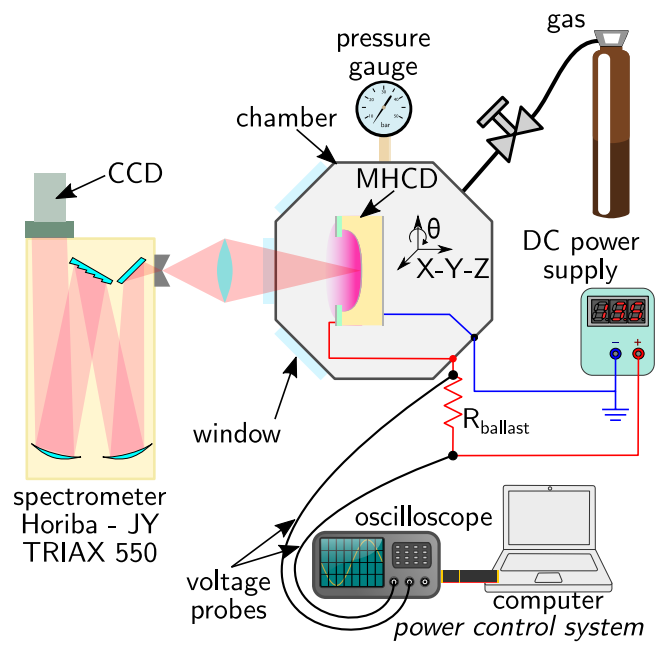

Figure 2. Synoptic of the experimental setup used for the space-resolved spectroscopy and electrical diagnostics. The MHCD is mounted on stage moving in three orthogonal direction X-Y-Z and can be rotated with an angle $\theta=90 \mathrm{deg}$.

and the current going through the cavity $\left(I_{\mathrm{MHCD}}\right)$, two voltage probes (Tek P5100, Tektronix) are connected to the terminals of $\mathrm{R}_{\text {ballast }}$. Both signals are acquired with an oscilloscope (DPO 2024B $200 \mathrm{MHz}$, Tektronix) and recorded with a computer. Each 
voltage waveform is processed to correct for the bias error induced by the impedance of the probes. In DC excitation regime, the power dissipated in the plasma is found according to $\mathrm{P}_{\mathrm{MHCD}}=\mathrm{I}_{\mathrm{MHCD}} \cdot \mathrm{V}_{\mathrm{MHCD}}$. To monitor the discharge, a computer program has been developed to measure in real-time each electrical parameter while adjusting the DC generator. This gives the advantage to set and to control $I_{\mathrm{MHCD}}$ and $\mathrm{P}_{\mathrm{MHCD}}$ accurately for reproducible conditions.

Optical measurements are carried out with an imaging spectrometer (TRIAX 550, Horiba J-Y) of $0.55 \mathrm{~m}$ focal length and equipped with two exchangeable gratings. A cooled CCD camera (DU440-BU, Andor) is used to record the spectra. The instrumental function is measured with the help of a HeNe laser and a neon Geissler tube and fits to a gaussian profile with a full-width at half maximum (FWHM) of $34 \pm 1 \mathrm{pm}$ at $632.8 \mathrm{~nm}$ and $23 \pm 1 \mathrm{pm}$ at $375.4 \mathrm{~nm}$ for the $1800 \mathrm{~g} / \mathrm{mm}$ and $2400 \mathrm{~g} / \mathrm{mm}$ gratings respectively. The entrance slit width was set to $30 \mu \mathrm{m}$. The light emitted from the micro-cavity passes through the quartz window of the chamber. It is then collected with an optical system with a magnification of 1.5 placed in front of the spectrometer slit. Achromatic and aspherical lenses are utilized to minimize the optical aberrations on the image of the micro-plasma in order to have a sufficient spatial resolution. Figure 3 presents an image of the plasma produced by the MHCD and captured with

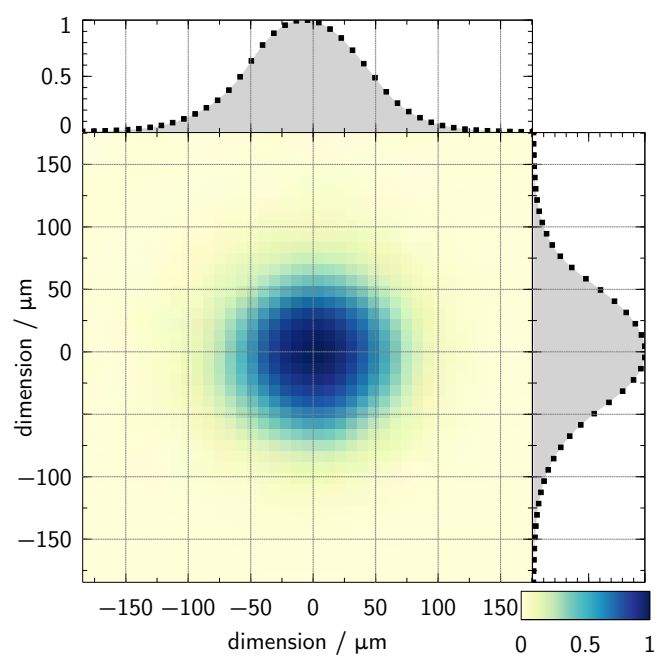

Figure 3. Front face MHCD imaged on the CCD of the spectrometer. The color scale is linear and normalized to the maximum intensity of the picture. The spectrometer is set at zero diffraction order with a large slit width $(2.0 \mathrm{~mm})$. The curves at the top and on the right side are intensity profiles of the sections taken along each axis at $0 \mu \mathrm{m}$. Discharge in He at $666 \mathrm{mbar}, \mathrm{I}_{\mathrm{MHCD}}=122 \mu \mathrm{A}$.

the imaging spectroscopic bench. Most of the light originates from the central region of the plasma located within the cavity. The recorded image resembles a perfect disc due to the axisymetry of the micro-cavity meaning that the optical aberrations are reduced below the spatial resolution of the CDD camera. Both intensity profiles taken at position $0 \mu \mathrm{m}$ of each axis validate the excellent uniformity of the image. Thus this optical diagnostic system has the capabilities to analyze the discharge emission originating from the plasma volume along the micro-cavity diameter. 
Iseni et al 2019, IOP PSST, doi:10.1088/1361-6595/ab1dfb

\section{Optical emission spectral analysis}

Optical diagnostics provide a powerful and convenient way to measure plasma parameters such as particle number densities and temperatures. In this section, two different approaches are described in order to determine experimentally the neutral gas temperature of the MHCD.

\subsection{Line broadening}

The study of atomic line shifting and broadening is a common approach to investigate discharges since the perturbation of a line from its natural broadening often results from multiple mechanisms inherent in the properties of the plasma. Experimental observations and theoretical descriptions of line shifting and broadening phenomena have been extensively reviewed in the literature [21, 22].

Close to atmospheric conditions, pressure effects are often the main reason of the line broadening [23]. Neutral atoms and molecules are mainly responsible for the so-called Van der Waals broadening (collisional broadening). Another line broadening affecting specific atomic transitions naturally governed by the pressure is named resonance broadening. Such line broadening is being investigated and used in the present study to measure the neutral gas temperature.

At elevated pressure, the Doppler broadening is often neglected. Indeed, Doppler broadening that contributes to the gaussian FWHM is estimated using standard formula [24] for the two observed atomic lines: Ar at $750.39 \mathrm{~nm}\left(2 \mathrm{p}_{1} \rightarrow 1 \mathrm{~s}_{2}\right)$ and $\mathrm{He}$ at $667.82 \mathrm{~nm}\left(3^{1} \mathrm{D} \rightarrow 2^{1} \mathrm{P}\right)$. The highest gas temperature for Ar MHCD is supposed to be around $900 \mathrm{~K}$. For the given temperature, Doppler broadening of the Ar line at $750.39 \mathrm{~nm}$ is about $2.6 \times 10^{-3} \mathrm{~nm}$. Similarly, the highest gas temperature in helium MHCD, which causes the highest Doppler broadening of helium lines, was estimated to be $500 \mathrm{~K}$. Thus the maximal contribution of this broadening mechanism to the gaussian FWHM of He $667.82 \mathrm{~nm}$ line is $5.4 \times 10^{-3} \mathrm{~nm}$.

Self-absorption is another known mechanism of radiation energy transfer which may affect the line shape of atomic transition. However, the line profile of the resonant transitions used in this work are not affected by self-absorption broadening in the present experimental conditions [25, 17]. Crosschecking was performed by measuring the line strength ratio of the atomic oxygen triplet. The results show a deviation lower than $3 \%$ with the reference data of NIST [26] which support the assumption of no self-absorption in the discharge.

Stark broadening of non-hydrogenic lines is a consequence of quadratic Stark effect due to electron impacts with radiating atoms. This broadening mechanism contributes to the lorentzian part of the line profile and it is weakly sensitive to the plasma microfield [24]. The effect is usually considered if the electron density exceed $5 \times 10^{15} / \mathrm{cm}^{3}$, which should be well above the maximal electron densities in studied MHCD in argon and helium [27, 28]. However, the effect of the electron density on the line profiles is estimated for both observed lines using STARK-B database [29]. The estimations were calculated for the maximal electron densities of $1 \times 10^{16} / \mathrm{cm}^{3}$ and electron temperature of $10^{4} \mathrm{~K}$ for the Ar MHCD and $1 \times 10^{15} / \mathrm{cm}^{3}$ and $10^{4} \mathrm{~K}$ for the He MHCD. For the given plasma parameters, Stark FWHM of Ar line at $750.39 \mathrm{~nm}$ is below $0.01 \mathrm{~nm}$ and He $667.82 \mathrm{~nm}$ line below $0.007 \mathrm{~nm}$ [30].

An estimation was possible for He MHCD electron density of $1 \times 10^{14} / \mathrm{cm}^{3}$ and electron temperature of $10^{4} \mathrm{~K}$ leading to a Stark FWHM of $7 \times 10^{-4} \mathrm{~nm}$. With 
the estimated values of Doppler and Stark contributions to the experimental line profiles, one concludes that these two broadening mechanisms have minor effects on the observed lines FWHM. Consequently, they can be safely neglected in further line profile analysis.

3.1.1. Resonance broadening This specific kind of broadening occurs for a radiative transition of an excited atom originating from or towards an energy level allowing for a dipole transition to the ground state of the emitters while the latter collides with identical atoms in the ground state [24]. It is a selective collisional broadening in a sense that only some peculiar lines of an atomic gas are affected. An example is shown in figure 4 where two lines of the $3 \mathrm{p}^{5} 4 \mathrm{p} \rightarrow 3 \mathrm{p}^{5} 4 \mathrm{~s}$ Ar transitions are differently broadened. Indeed, the $\mathrm{s}_{2}$ level of Ar belongs to a strong resonant state while the $\mathrm{s}_{4}$

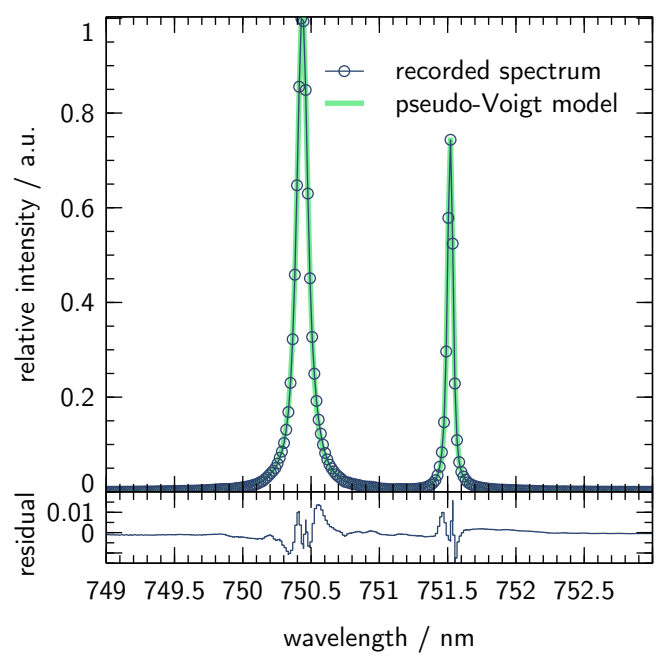

Figure 4. Ar spectrum of a resonance transition at $750.39 \mathrm{~nm}\left(2 \mathrm{p}_{1} \rightarrow 1 \mathrm{~s}_{2}\right)$ and a non-resonance transition at $751.46 \mathrm{~nm}\left(2 \mathrm{p}_{5} \rightarrow 1 \mathrm{~s}_{4}\right)$. The discharge current was set to $171 \pm 5 \mu \mathrm{A}$ at a pressure of $666 \mathrm{mbar}$. $T_{\mathrm{g}}$ was estimated to be $669 \pm 25 \mathrm{~K}$.

level is by orders less resonant and might be broadened by other mechanisms and the instrumental function otherwise.

The resonance transition mechanism has been widely studied and its theoretical concept is well documented [31,25]. A convenient way to describe the resonance broadening is through its contribution to the Lorentzian FWHM of the atomic line, $w_{\mathrm{R}}$. It may be expressed as

$$
w_{\mathrm{R}}=K(0,1) \frac{r_{\mathrm{e}}}{\pi} \sqrt{\frac{g_{\mathrm{G}}}{g_{\mathrm{R}}}} \lambda_{0}^{2} \lambda_{\mathrm{R}} f_{\mathrm{R}} N_{\mathrm{R}}
$$

where $r_{\mathrm{e}}$ is the classical electron radius, $g_{\mathrm{G}}$ and $g_{\mathrm{R}}$ are the statistical weights of the ground and the resonant state respectively. $f_{\mathrm{R}}$ is the oscillator strength of the resonance transition of wavelength $\lambda_{R}$. Depending on the atomic gas, the corresponding values for the latter coefficients can be found in the NIST database [26]. $\lambda_{0}$ is the central wavelength of one of the lines affected by the resonance and being investigated. Conveniently, $w_{\mathrm{R}}$ is directly proportional to the ground state density number $N_{\mathrm{R}}$ of the emitters resulting in a significant resonance broadening in conditions 
close to atmospheric pressure.

The coefficient $K(0,1)$ of $(1)$ is related to the total angular momenta of the ground and resonant state. In the case of noble gases, several works have determined its value to be approximately 1 , although a lack of matching data from the literature has been recently addressed in [32]. Over the past decade, 0.96 was commonly used as a value for $K(0,1)[24]$. Recently, Pipa et al have published a comprehensive discussion on this topic based on many experimental and theoretical works [32]. The authors offered to reevaluate this coefficient based on extended literature review and suggest $K(0,1)=1.04$ as the most probable value. The latter will be used in the present study.

3.1.2. Van der Waals broadening Apart from the selective resonance broadening, Van der Waals broadening and shift are universally affecting all atomic transitions. The latter results from the dipolar interaction between excited atoms and the induced dipole from all kind of neutral colliders. The theory of the Van der Waals broadening mechanism is complex but has been extensively studied: a detailed description can be found in $[31,33]$. A practical and well-known expression [34, 35] giving its contribution to the Lorentzian FWHM of and atomic line $w_{\mathrm{vdw}}$ reads,

$$
w_{\mathrm{vdw}}[\mathrm{cm}]=8.18 \cdot 10^{-12} \lambda_{0}^{2}\left(\bar{\alpha} \bar{R}^{2}\right)^{2 / 5}\left(\frac{T_{\mathrm{g}}}{\mu}\right)^{3 / 10} \cdot N,
$$

where $\lambda_{0}$ is the wavelength of the observed atomic transition, $\bar{\alpha}$ is the average polarizability of the neutral collider [36], $\mu$ is the reduced mass of the emitter-collider system and $\bar{R}$ is the difference between the values of the coordinate vector of radiating electron in the excited state [33]. As a matter of fact, $w_{\mathrm{vdw}}$ is proportional to the total number density $N$ and also depends on the neutral gas temperature $T_{\mathrm{g}}$. To complete the broadening description (2), the theory predicts that a shift of the line to the red is also affecting the transition. It is approximately estimated to one-third of $w_{\mathrm{vdw}}$ but it is negligible under our experimental conditions simply due to the instrumental function.

Quantitatively -in plasmas close to atmospheric pressure- the observed broadening of atomic lines is -with the exception of the resonance transitions- a competition between the contribution of $w_{\mathrm{vdw}}$ and the instrumental function if not dominated by the latter otherwise [24].

\subsection{Measure of the neutral gas temperature $-T_{\mathrm{g}}$}

Considering the above broadening descriptions and their close dependence with neutral number density of weakly ionized gas $\left(N_{\mathrm{R}} \approx N\right)$, it is possible to determine $T_{\mathrm{g}}$. Depending on the discharge gas, the line profile of the resonance transition of $\mathrm{Ar}$ at $750.39 \mathrm{~nm}\left(2 \mathrm{p}_{1} \rightarrow 1 \mathrm{~s}_{2}\right)$ or He at $667.82 \mathrm{~nm}\left(3^{1} \mathrm{D} \rightarrow 2^{1} \mathrm{P}\right)$ are observed and analyzed. Both lines are chosen for their strong emission intensity, their separation from other neighboring emissions and their spectral position in the visible range.

To obtain a value of the Lorentzian FWHM of each broadening depending on $T_{\mathrm{g}}$, (1) and (2) are expressed in a more convenient form as,

$$
\begin{aligned}
& w_{\mathrm{R}}[\mathrm{nm}]=\kappa_{\mathrm{R}} \cdot \frac{p[\mathrm{~Pa}]}{T_{\mathrm{g}}[\mathrm{K}]}, \\
& w_{\mathrm{vdw}}[\mathrm{nm}]=\kappa_{\mathrm{vdw}} \cdot \frac{p[\mathrm{~Pa}]}{T_{\mathrm{g}}^{0.7}[\mathrm{~K}]} .
\end{aligned}
$$


The coefficients $\kappa_{\mathrm{R}}$ and $\kappa_{\mathrm{vdw}}$ are transition specific. The calculated values are given in table 1 taking into account the recent correction of $K(0,1)$ suggested in [32] for the resonance broadening. Consequently, the FWHM of the Lorentzian contribution $\left(w_{\mathrm{L}}\right)$

Table 1. Coefficients used in (3) and (4) for the determination of the Lorentzian FWHM of the resonance and the Van der Waals broadening.

\begin{tabular}{cccc}
\hline & $\lambda_{0}[\mathrm{~nm}]$ & $\kappa_{\mathrm{R}}\left[10^{-5} \mathrm{~nm} \mathrm{~K} / \mathrm{Pa}\right]$ & $\kappa_{\mathrm{vdw}}\left[10^{-5} \mathrm{nmK}^{0.7} / \mathrm{Pa}\right]$ \\
\hline $\mathrm{Ar}$ & 750.3869 & 57.56 & 2.28 \\
$\mathrm{He}$ & 667.8151 & 28.08 & 1.77 \\
\hline
\end{tabular}

to the measured line shape can be expressed as,

$$
w_{\mathrm{L}} \approx w_{\mathrm{R}}+w_{\mathrm{vdw}},
$$

being inversely proportional to $T_{\mathrm{g}}$.

Experimentally, the profile of a line is known to be a convolution of the instrumental function (Gaussian type) with -in our case- the sum of each pressure broadening having a Lorentzian profile. To analyze the line shape of the recorded spectra and to infer $T_{\mathrm{g}}$ from $w_{\mathrm{L}}$, the line is fitted to a pseudo-Voigt distribution function, $f\left(\lambda ; A, \lambda_{0}, \sigma, \eta\right)$. Figure 5 shows a typical spectrum of the resonance transition of He at $667.82 \mathrm{~nm}$ fitted with a pseudo-Voigt function, which is an analytical approximation of the Voigt function. The pseudo-Voigt profile (6) is a linear combination of a Gaussian

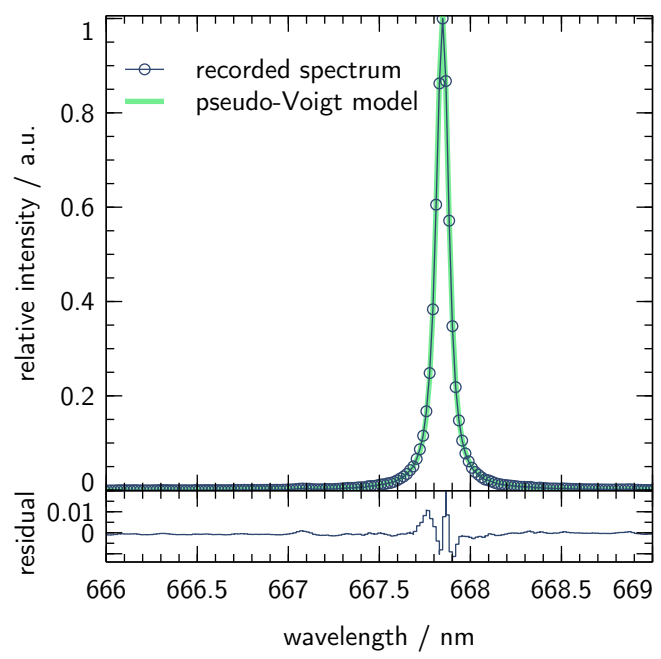

Figure 5. Typical line shape of the resonant transition of $\mathrm{He}$ at $667.82 \mathrm{~nm}$ $\left(3^{1} \mathrm{D} \rightarrow 2^{1} \mathrm{P}\right)$. The discharge current was set to $71 \pm 2 \mu \mathrm{A}$ at a pressure of 666 mbar. $T_{\mathrm{g}}$ was estimated to be $374 \pm 14 \mathrm{~K}$.

profile and a Lorentzian profile balanced with the parameter $\eta$ ranging from 0 to 1 . Both parts are normalized to share the same amplitude $A$, the same central value $\lambda_{0}$ and a constrained width with the parameter $\sigma$ giving the following expression,

$$
f\left(\lambda ; A, \lambda_{0}, \sigma, \eta\right)=A \frac{(1-\eta)}{\sigma_{\mathrm{g}} \sqrt{2 \pi}} \exp \left[-\frac{\left(\lambda-\lambda_{0}\right)^{2}}{2 \sigma_{\mathrm{g}}^{2}}\right]+\frac{A \eta}{\pi}\left[\frac{\sigma}{\left(\lambda-\lambda_{0}\right)^{2}+\sigma^{2}}\right],(6)
$$


where $\sigma_{\mathrm{g}}=\sigma / \sqrt{2 \ln 2}$ so that the FWHM of each component and of the sum is $2 \sigma$. The advantage of using a pseudo-Voigt function -instead of a Voigt function- is the limited number of fitting parameters, its explicit computation and the pragmatical nature of the approximation allowing for a clear identification of each underlying contribution to the line shape structure [37].

Finally, the Lorentzian part $w_{\mathrm{L}}$ of the line shape is deduced with a simple series expansion as,

$$
\eta=1.36603\left(w_{\mathrm{L}} / 2 \sigma\right)-0.47719\left(w_{\mathrm{L}} / 2 \sigma\right)^{2}+0.11116\left(w_{\mathrm{L}} / 2 \sigma\right)^{3},
$$

with a maximum inaccuracy of $1 \%$ depending on the value of $\eta[38]$.

\subsection{Rotational temperature of $N_{2}(C-B)-T_{\text {rot }}$}

Another approach to determine the neutral gas temperature of non-thermal plasmas is to study the rotational distribution of -diatomic- molecules. This is carried out by recording the emission spectra of a ro-vibrational molecular band and after analysis of the relative intensity of each rotational state. The method is commonly used in plasmas operated at elevated pressure simply because of the high collision frequency which will support the thermalisation of the rotational population distributions. The assumptions to consider the translational temperature equal to the rotational temperature $\left(T_{\text {rot }}\right)$ are detailed in [39].

Potentially, all excited molecular states can be used to have an idea about the neutral gas temperature although some molecular spectra may have some of their ro-vibrational structure disturbed due to competitive excitation, deexcitation and quenching processes as reported in [39, 40]. In this work, $T_{\text {rot }}$ of $\mathrm{N}_{2}(\mathrm{C}-\mathrm{B})$-or second positive system- will be studied. Conveniently, traces of $\mathrm{N}_{2}$ often remain as impurities within the gas chamber and yields an intense emission easy to record in the near-UV. An example of a rotational spectrum of $\mathrm{N}_{2}(\mathrm{C}-\mathrm{B})$-with $v^{\prime}=1$ the upper vibrational state and $v^{\prime \prime}=3$ the lower level- is shown in figure 6 . To analyze the recorded spectra, a numerical curve optimization algorithm is used to fit a simulated rotational distribution intensity spectrum. For a given vibrational transition $\left(v^{\prime} \rightarrow v^{\prime \prime}\right)$ of $\mathrm{N}_{2}(\mathrm{C}-$ B), each relative rotational transition intensity $I_{J^{\prime \prime}}^{J^{\prime}}$ is proportional to,

$$
I_{J^{\prime \prime}}^{J^{\prime}} \propto N_{v^{\prime}} S_{J^{\prime \prime}}^{J^{\prime}}\left(\nu_{v^{\prime \prime} J^{\prime \prime}}^{v^{\prime} J^{\prime}}\right)^{4} \exp \left[-\frac{h c}{k_{\mathrm{B}} T_{\mathrm{rot}}} F_{v^{\prime}}^{(1,2,3)}\left(J^{\prime}\right)\right]
$$

with $J^{\prime}$ and $J^{\prime \prime}$ the upper and lower rotational excited states respectively. $N_{v^{\prime}}$ is the number density of $\mathrm{N}_{2}(\mathrm{C}-\mathrm{B})$ in the excited state $v^{\prime}$ and $S_{J^{\prime \prime}}^{J^{\prime}}$ is the line strength -or Hönl-London factor as triplets of $\mathrm{N}_{2}(\mathrm{C}-\mathrm{B})$ belong to the intermediate case between Hund case (a) and (b) [41] - theoretically described by Kovacs for all type of transitions

and couplings [42]. $\nu_{v^{\prime \prime} J^{\prime \prime} J^{\prime \prime}}^{v^{\prime}}$ is the transition frequency and $F_{v^{\prime}}^{(1,2,3)}\left(J^{\prime}\right)$ is the rotational spectral term [41] depending on the vibrational quantum number $v^{\prime}$. The latter quantities are calculated according to the set of spectroscopic constants published by Roux et al [43].

The spectrometer is set to record in a single frame three rotational emission bands of $\mathrm{N}_{2}$ (C-B): (0-2), (1,3) and (2-4) with the band heads observed at $380.5 \mathrm{~nm}, 375.5 \mathrm{~nm}$ and $371.0 \mathrm{~nm}$ respectively [44]. To take into account the spectral response of the system, a calibrated deuterium lamp is used to correctly set the relative intensity of the spectra. 


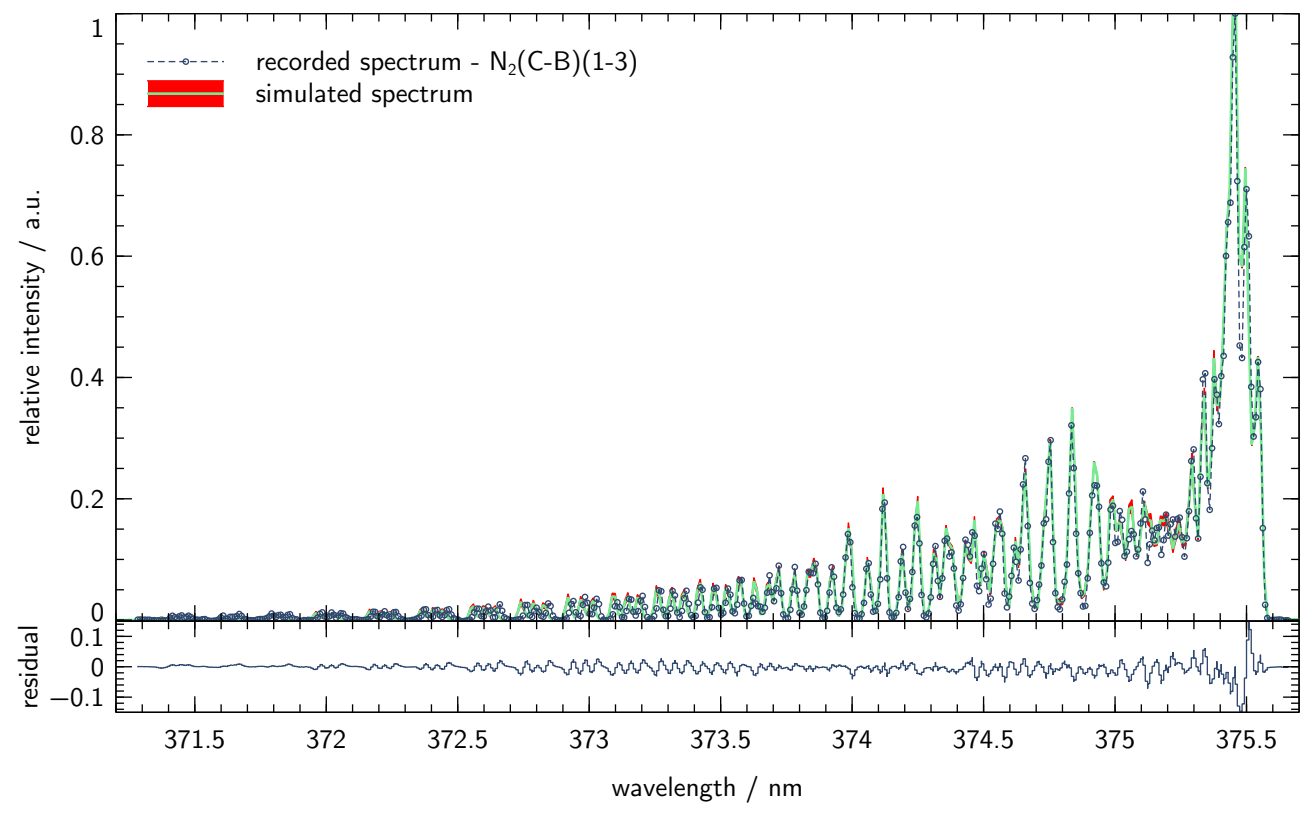

Figure 6. Experimental and simulated rovibrational emission distribution of $\mathrm{N}_{2}$ (C-B)(1-3). $\quad T_{\text {rot }}=447 \pm 15 \mathrm{~K}$ is determined from the fitting curve optimization with $95 \%$ confidence interval. The latter surrounds the simulated spectrum line in red. Discharge in pure $\mathrm{N}_{2}$ at 266 mbar with $I_{\mathrm{MHCD}}=101 \pm 3 \mu \mathrm{A}$.

\subsection{Error analysis and uncertainties}

In experimental work, error analysis of measured values is a key to determine the reproducibility of the observations, the validity and the limits of each diagnostic method [45]. While dealing with emission spectroscopy techniques -essentially based on complex formalisms involving tangled constants- it is somewhat necessary to estimate uncertainties of the outcome.

Regarding the determination of $T_{\text {rot }}$, the fitting routine was developed accounting for -only- four adjustable parameters namely $T_{\text {rot }}$, the FWHM of the instrumental function, a coefficient to shift the wavelength scale and an optional parameter to correct for the non-linearity of the spectral dispersion. This reduced parameter set offers the advantage of a robust fit narrowing significantly the range of values for $T_{\text {rot }}$. To enhance the reliability of the outcome, the optimization procedure is twofold. First, a differential evolution algorithm is used to determine the parameter ranges related to the global minimum. In a second step, a gradient method based on the Levenberg-Marquardt algorithm allows of optimizing the value of each parameters. To quantify $T_{\text {rot }}$ uncertainties, a confidence interval is systematically computed with $95 \%$ probability leading to typical relative errors of $3 \%$ to $6 \%$.

Concerning the measurement of $T_{\mathrm{g}}$ described in section 3.2, the approach is the following. $\delta T_{\mathrm{g}}$ is defined as uncertainty in $T_{\mathrm{g}}$. From (5) one can consider $\delta \tilde{w}$ as the global uncertainties in the Lorentzian FWHM of the experimental atomic line shape such as,

$$
\delta \tilde{w}=\delta w_{\mathrm{L}}+\delta w_{\mathrm{R}}+\delta w_{\mathrm{vdw}}
$$


with $\delta w_{\mathrm{L}}$ being twice the standard deviation of $w_{\mathrm{L}}$, found after optimization of the pseudo-Voigt profile with the experimental spectra. The uncertainties $\delta w_{\mathrm{R}}$ and $\delta w_{\mathrm{vdw}}$ are related to $w_{\mathrm{R}}$ and $w_{\mathrm{vdw}}$ respectively. According to (5), these coefficients read,

$$
\begin{aligned}
& \delta w_{\mathrm{R}}^{2}=\left(p T_{\mathrm{g}}^{-1}\right)^{2} \cdot \delta \kappa_{\mathrm{R}}^{2}+\left(\kappa_{\mathrm{R}} T_{\mathrm{g}}\right)^{2} \cdot \delta p^{2}, \\
& \delta w_{\mathrm{vdw}}^{2}=\left(p T_{\mathrm{g}}^{-0.7}\right)^{2} \cdot \delta \kappa_{\mathrm{vdw}}^{2}+\left(\kappa_{\mathrm{vdw}} T_{\mathrm{g}}^{-0.7}\right)^{2} \cdot \delta p^{2},
\end{aligned}
$$

with the fractional uncertainties estimated from the literature and reported in table 2. In case of $\mathrm{N}_{2}$ admixture up to $1 \%$, the coefficient $\kappa_{\mathrm{vdw}}$ should be recalculated

Table 2. Typical fractional uncertainties estimations for the coefficients used to calculate $\delta \tilde{w}$. The values are based on literature review or from the experiments of this work.

\begin{tabular}{lcl}
\hline coefficient & fractional uncertainties & ref. \\
\hline$\delta \kappa_{\mathrm{R}}$ & $4 \%$ & {$[24,32]$} \\
$\delta \kappa_{\mathrm{vdw}}$ & $10 \%$ & {$[24,33,46,36]$} \\
$\delta p$ & $2 \%$ & instrument \\
$\delta w_{\mathrm{L}}$ & $<1 \%$ & fit model \\
\hline$\delta T_{\mathrm{g}}$ & $<4 \%$ & this work \\
\hline
\end{tabular}

accordingly due to the additional nature of the potential colliders. However, the low $\mathrm{N}_{2}$ fraction leads to a relative variation of $\kappa_{\mathrm{vdw}}$ below its fractional uncertainties $\delta \kappa_{\mathrm{vdw}}$. The fractional uncertainties $\delta \kappa_{\mathrm{vdw}}$ Consequently, an upper and a lower bounds of $T_{\mathrm{g}}$ can be inferred from (5) taking into account $\delta \tilde{w}$ such as,

$$
w_{\mathrm{L}} \pm \delta \tilde{w} \rightarrow\left\{\begin{array}{l}
T_{\mathrm{g}}^{\min } \\
T_{\mathrm{g}}^{\max }
\end{array}\right.
$$

which lead to determine trustful values of $\delta T_{\mathrm{g}}$ as a realistic and meaningful uncertainties in $T_{\mathrm{g}}$. A maximum value of $\delta T_{\mathrm{g}}$ is reported in table 2 based of the experimental data obtained in this work.

\section{Results and discussion}

\subsection{Electrical measurements}

Typical electrical characteristics of the MHCD operating in He $(666 \mathrm{mbar})$ and supplied by a stabilized DC generator are presented on figure 7 . The voltage and current curves are shown in figure 7a). During the first $4 \mathrm{~s}$ the voltage increases up to $200 \mathrm{~V}$ where the breakdown occurs leading to the ignition of the discharge. The related nested plot shows the breakdown time with the classical voltage drop and a simultaneous current rise. From this moment up to $10 \mathrm{~s}$, the voltage source is adjusted to set a desired value of $I_{\mathrm{MHCD}}$, e.g. $394 \pm 5 \mu \mathrm{A}$ corresponding to a power as high as $72 \pm 2 \mathrm{~mW}$ in the case reported on figure $7 \mathrm{a}$ ). The optical measurements are realized when the stable regime is reached. Figure 7b) presents the $I-V$ characteristic curve known for classical glow discharges with the difference that the voltage is never strictly independent of the current value. First note that current and voltage of the discharge are particularly stable as compared to the previous configurations studied in [47]. To avoid any confusion with the definition of the normal regime, this regime is called quasi-normal [19]. The latter reference reported on an hysteresis which is also 

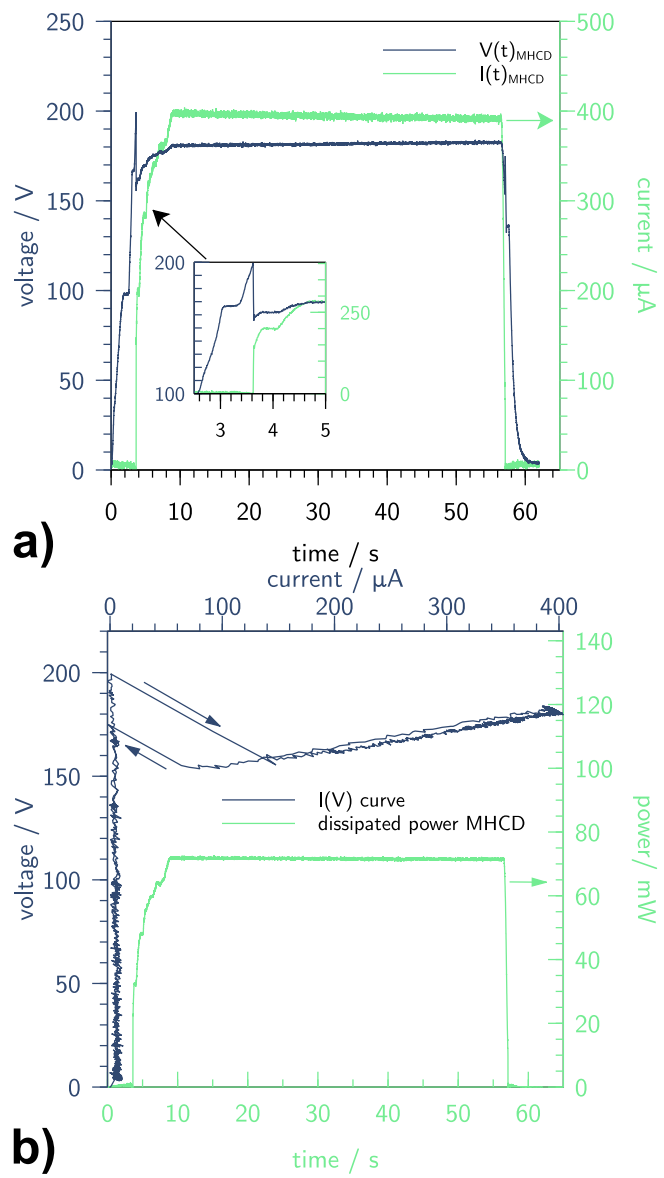

Figure 7. Electrical characteristics of a single MHCD reactor operated in $\mathrm{He}$ at 666 mbar. a) shows the time evolution of $V_{\mathrm{MHCD}}$ and $I_{\mathrm{MHCD}}$. b) is the classical $I$ - $V$ characteristic together with the instantaneous power.

observed but not clearly identified. It is important to note that the current, voltage and dissipated power are remarkably stable over the time and during the measurement even at power densities as high as $2.9 \times 10^{5} \mathrm{~W} / \mathrm{cm}^{3}$. The region of negative slope reported in [48] on the $I-V$ characteristic is not observed in the present case due to the rather thin dielectric layer allowing for a contiguous expansion of the plasma onto the anode surface.

\section{2. $T_{\mathrm{g}}$ in $\mathrm{Ar}$ and He discharges}

The neutral gas temperature is firstly measured in pure noble gases. Figure 8 presents $T_{\mathrm{g}}$ dependence of $I_{\mathrm{MHCD}}$ for $\mathrm{He}$ and $\mathrm{Ar}$ showing significant differences. For both gases, $T_{\mathrm{g}}$ is calculated from the resonance broadening without the Van der Waals contribution. The data evaluation is twofold: once involving the commonly used value of $K(0,1)$ and a second time with the recent reevaluation suggested by Pipa et al [32] (cf. discussion in section 3.1.1). Depending on the value used for $K(0,1)$, the impact on $T_{\mathrm{g}}$ in He discharge does not exceed $30 \mathrm{~K}$. However, $T_{\mathrm{g}}$ seems to be 


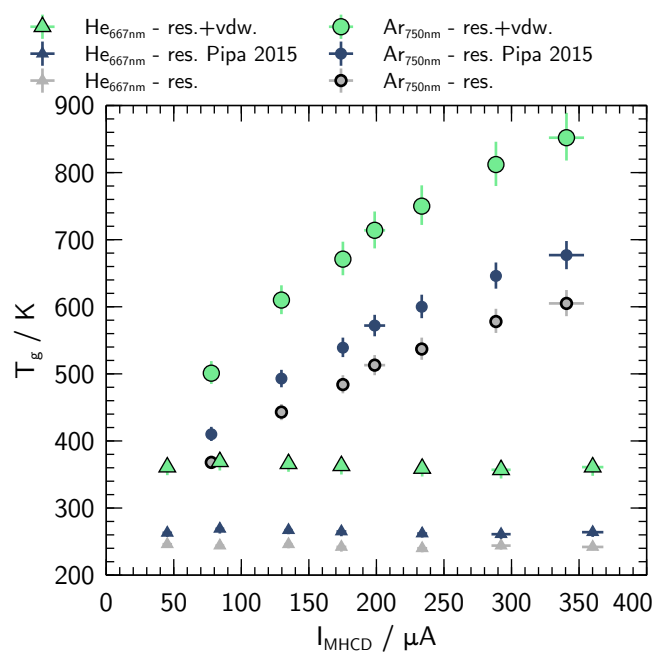

Figure 8. $T_{\mathrm{g}}$ inside the cavity of the MHCD operating in Ar and He gases taking into account the resonant broadening and the Van der Waals contribution. The pressure was set to 666 mbar. Data labeled Pipa 2015 refers to the discussion in section 3.1.1 and the references therein.

underestimated with values around $270 \mathrm{~K}$ which is below the room temperature. This fact reveals that the analysis of the line considering solely the resonant broadening is not satisfying. The same evaluation is shown in the case of $\mathrm{Ar}$ where the values found for $T_{\mathrm{g}}$ are more realistic although the choice of the resonance constant can yield deviations up to $100 \mathrm{~K}$.

To illustrate substantially the necessity to take into account -in the present case- the Van der Waals broadening as a correction to the resonance broadening contributing to $w_{\mathrm{L}}$, both data sets are analyzed according to equation (5). A significant correction on $T_{\mathrm{g}}$ ranging from $100 \mathrm{~K}$ to $180 \mathrm{~K}$ is observed for both gases. As a matter of fact, this evidences that in room temperature plasmas, the determination of $T_{\mathrm{g}}$ by emission spectroscopy requires an adequate description of the broadening mechanisms to infer reasonable values of $T_{\mathrm{g}}$. As a matter of fact, $T_{\mathrm{g}}$ in He is now found to be in a realist range, above room temperature. Remarkably, the temperature of the discharge in $\mathrm{He}$ stays constant around $360 \mathrm{~K}$ which means that $T_{\mathrm{g}}$ inside the cavity is independent of $I_{\mathrm{MHCD}}$ considering the investigated current range.

However in case of $\mathrm{Ar}, T_{\mathrm{g}}$ increases significantly with the current to reach values up to $850 \mathrm{~K}$ without damaging the micro-reactor. These results are in very good agreement with the temperatures reported in $[15,13]$ for DC MHCD in Ar with different geometries. While in the present case the power density is estimated to be about one order of magnitude higher than in the referred studies, a similar dynamic of $T_{\mathrm{g}}$ depending on $I_{\mathrm{MHCD}}$ is observed.

The main reason to explain the temperature behavior between the two gases is the thermal conductivity of $\mathrm{He}$ which is about 8.5 times larger than for Ar in the temperature range from $300 \mathrm{~K}$ to $600 \mathrm{~K}$ [49]. As a consequence, it is expected that in the case of $\mathrm{He}$, the heat flux is efficiently transferred into the wall of the microreactor and by convection with the cooler gas in the vicinity of the outlet. This means that $T_{\mathrm{g}}$ is mostly determined by the type of the gas rather than the geometry of the 
micro-reactor.

\section{3. $T_{\mathrm{g}}$ in Ar with $N_{2}$ admixture}

The gas temperature is evaluated from the line broadening of resonant lines in case of small amount of molecular gases added to the discharge. It is known that in $\mathrm{Ar} / \mathrm{N}_{2}$ discharge, an efficient quasi-resonant energy transfer between two metastable states $\operatorname{Ar}\left({ }^{3} \mathrm{P}_{2}\right)$ and $\operatorname{Ar}\left({ }^{3} \mathrm{P}_{0}\right)$ with $\mathrm{N}_{2}$ occurs [50]. This excitation mechanism competes with a direct electron impact excitation leading to an overpopulation of high $J$ of the vibrational bands. Thus their relative intensity distributions are not described by equation 8 and $T_{\text {rot }}$ of $\mathrm{N}_{2}$ cannot be measured because the rotational population distributions are not in equilibrium. Therefore, it is interesting to investigate the influence of small admixture of $\mathrm{N}_{2}$ in a DC MHCD in Ar on the neutral gas temperature using the resonant line profile analysis.

A fraction of $\mathrm{N}_{2}$ is mixed with Ar considering the quasi-resonant energy coupling between some Ar metastable states with this diatomic molecule. The results are shown in figure 9 . The effect of $\mathrm{N}_{2}$ fraction is not that significant on $T_{\mathrm{g}}$ in Ar mixture.

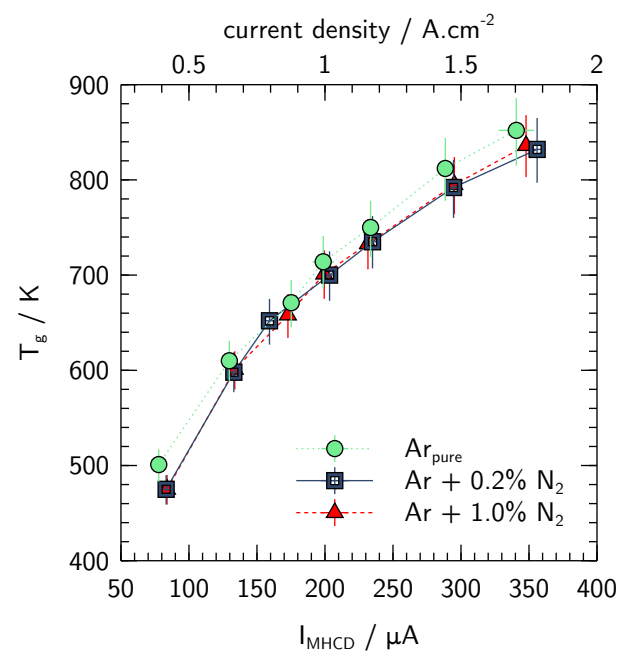

Figure 9. $T_{\mathrm{g}}$ in the cavity of the MHCD operating in Ar with small admixture of $\mathrm{N}_{2}$. The pressure was set to 666 mbar.

The trend of the curve is the same as in pure Ar. At constant current, a slight decrease of $T_{\mathrm{g}}$ due to $\mathrm{N}_{2}$ is attributed to a redistribution of energy to excite the ro-vibrational states. Unexpectedly the rotational to translational energy transfer does not increase $T_{\mathrm{g}}$. As a matter of fact, admixtures of $0.2 \%$ to $1.0 \%$ of $\mathrm{N}_{2}$ in Ar have the same effect on $T_{\mathrm{g}}$. Although for the three curves and at constant current, values of $T_{\mathrm{g}}$ are within the uncertainty range, a minor tendency to cool down the gas temperature can be mentioned.

\section{4. $T_{\text {rot }}$ in pure $N_{2}$}

The case of DC MHCD operated in $\mathrm{N}_{2}$ gas is investigated focusing on the neutral gas temperature. Since no any $\mathrm{Ar}$ neither He atoms are present in the discharge, 
the method to evaluate $T_{\mathrm{g}}$ from the line shape is substituted by studying the rotational temperature of $\mathrm{N}_{2}(\mathrm{C}-\mathrm{B})$. Figure 10 presents the results of $T_{\text {rot }}$ for several ro-

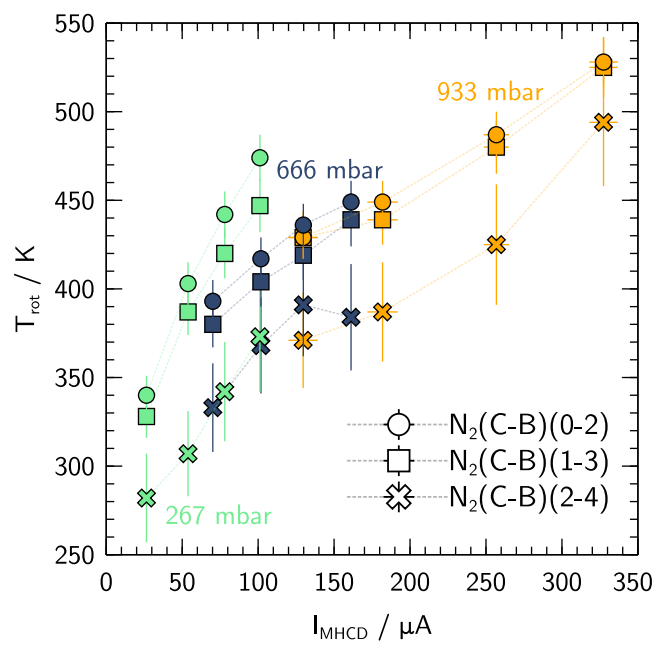

Figure 10. Rotational temperatures of MHCD in pure $\mathrm{N}_{2}$ discharge for three different pressure conditions (colored symbols: 267 mbar in green, 666 mbar in blue and 933 mbar in orange.) considering three vibrational bands of $\mathrm{N}_{2}(\mathrm{C}-\mathrm{B})$ recorded simultaneously.

vibrational bands and three different pressure conditions, namely $267 \mathrm{mbar}$, $666 \mathrm{mbar}$ and 933 mbar. At the first glance -and with the assumption that $T_{\text {rot }}$ is in equilibrium with the translational energy - the range of neutral gas temperature in $\mathrm{N}_{2}$ DC MHCD seems to be lower than in $\mathrm{Ar}$ as shown in figure 9. One notes that the thermal conductivity of $\mathrm{N}_{2}$ is about 1.5 times larger than Ar. Interestingly for each pressure condition, $T_{\text {rot }}$ of the three ro-vibrational bands have reasonably the same slope. However, the discrepancies between $T_{\text {rot }}$ values of $\mathrm{N}_{2}(\mathrm{C}-\mathrm{B})(0-2)$ or $\mathrm{N}_{2}(\mathrm{C}-\mathrm{B})(1-3)$ with $\mathrm{N}_{2}$ (C-B)(2-4) evidences some issues with the thermalization of higher ro-vibrational states. The radiative lifetime $\left(\tau_{\mathrm{C}}\right)$ of $\mathrm{N}_{2}(\mathrm{C})$ is $36.6 \mathrm{~ns}$ [51]. In pure nitrogen plasma, the quenching of $\mathrm{N}_{2}(\mathrm{C})$ is dominated by $\mathrm{N}_{2}$ in the ground state. Considering the quenching rate $k_{\mathrm{N}_{2}}^{\mathrm{C}}=1.1 \times 10^{-11} \mathrm{~cm}^{3} / \mathrm{s}$ [51], the lifetime of $\mathrm{N}_{2}(\mathrm{C})$ is significantly reduced to $4 \mathrm{~ns}$ for a plasma at $933 \mathrm{mbar}$ and $300 \mathrm{~K}$. In these conditions, the rotational-to-translational energy transfer (R-T) between the gas in the ground state with $\mathrm{N}_{2}(\mathrm{C})$ occurs in the same timescale as the spontaneous emission. Values from the literature and suggested in the review article [39] are used to estimate $\tau_{\mathrm{R}-\mathrm{T}}$-the time between R-T collisionsleading to $2 \mathrm{~ns} \leqslant \tau_{\mathrm{R}-\mathrm{T}} \approx \tau_{\mathrm{C}} \leqslant 11 \mathrm{~ns}$. The competition between both processes may disturb the equilibrium of the rotational population distribution of each vibrational level. However, the relatively high electron number density in MHCDs and the large majority of ground state $\mathrm{N}_{2}(\mathrm{X})$ implies that the direct electron impact excitation,

$$
\mathrm{N}_{2}(\mathrm{X}, v=0, J)+\mathrm{e}^{-} \stackrel{k_{\mathrm{e}}}{\longrightarrow} \mathrm{N}_{2}\left(\mathrm{C}, v^{\prime}, J^{\prime} \approx J\right)+\mathrm{e}^{-}
$$

is the dominant mechanism to populate the C-state. Typical values of the electron excitation rate $\left(k_{\mathrm{e}}\right)$ are documented in [39]. Consequently, the fast excitation from $\mathrm{N}_{2}(\mathrm{X})$ state -being in R-T equilibrium- prevents significant changes of the rotational angular momentum allowing for a transfer of the rotational population 
distribution from the ground state to the $\mathrm{N}_{2}(\mathrm{C})$ state. A thorough analysis of $\mathrm{N}_{2}(\mathrm{C}-$ B) ro-vibrational spectra to interpret $T_{\text {rot }}$ has been published in [10]. The authors developed an extended argumentation considering more general cases [40] leading to the conclusion that in the conditions of this study, $T_{\text {rot }}$ of $\mathrm{N}_{2}(\mathrm{C}-\mathrm{B})(0-2)$ reasonably equals $T_{\mathrm{g}}$. Regarding $T_{\text {rot }}$ found for the $\mathrm{N}_{2}(\mathrm{C}-\mathrm{B})(2-4)$ band, the discrepancies may be due to vibrational quenching within the $\mathrm{C}$-state which will be discussed later on.

In the present case, $T_{\text {rot }}$ values of $\mathrm{N}_{2}(\mathrm{C}-\mathrm{B})(0-2)$ and $\mathrm{N}_{2}(\mathrm{C}-\mathrm{B})(1-3)$ are significantly close for each pressure condition. At constant value of $I_{\mathrm{MHCD}}$, the rise of $T_{\text {rot }}$ with the pressure is consistent with the expectation on the gas temperature. Based on the latter facts, $T_{\text {rot }}$ of both ro-vibrational bands estimates in a credible range the neutral gas temperature of the discharge in pure $\mathrm{N}_{2}$. As a matter of fact, the gas temperatures are much lower than in Ar and are in agreement with values published in [12]. In the latter article, the same three ro-vibrational bands are recorded while $T_{\text {rot }}$ is measured for $\mathrm{N}_{2}(\mathrm{C}-\mathrm{B})(0-2)$ only. The authors reported on difficulties to fit some sets of spectra with other bands which can be a consequence of the non-equilibrium rotational population distributions, particularly for $\mathrm{N}_{2}(\mathrm{C}-\mathrm{B})(2-4)$ as also observed in the present work.

\section{5. $T_{\mathrm{g}}$ within and out of the cavity}

The idea to measure $T_{\mathrm{g}}$ in He and Ar gas at the surface of the cavity is realized by rotating the MHCD by $\theta=90^{\circ}$ (cf. figure 2). This approach is considered in order to complete prior spectroscopic measurements performed front-on while the whole light emitted by the plasma volume is collected. Although the diagnosed position on a 2D plane parallel to the reactor surface is well defined (cf. figure 3), the information along the cavity axis (i.e. the cavity depth) is not clear. By imaging the small He plasma volume expanding onto the anode surface, one can infer values of $T_{\mathrm{g}}$ and have a better insight on the thermal gradient. An illustration of the observation directions is shown

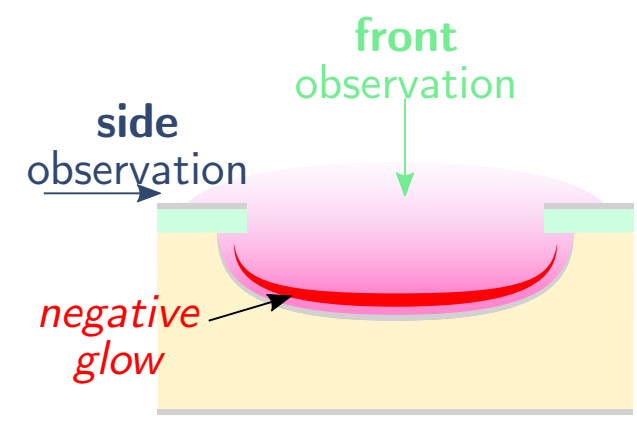

Figure 11. Sketch of the light intensity distribution and light collection from a single MHCD cavity with respect to the front and the side observation directions.

in figure 11.

$T_{\mathrm{g}}$ obtained from spectroscopic observations performed on the side of the He and Ar MHCD are presented in figure 12. It is important to note that the emission intensity collected front-on is much more intense than from the side. As $T_{\mathrm{g}}$ is related to the spectral line shape -and not to the magnitude of the signal- the recorded line profile results from the contribution of all emitters along the imaged plasma volume. 

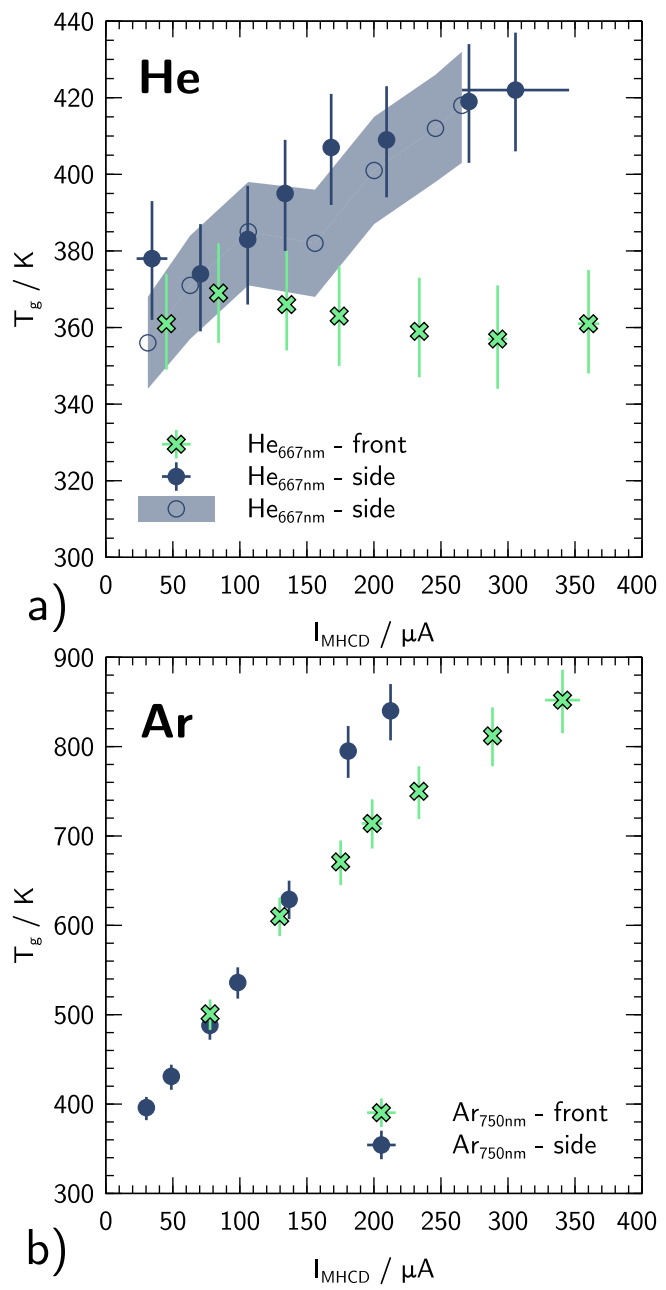

Figure 12. Comparison of $T_{\mathrm{g}}$ within (front) the MHCD cavity and outside (side) for a) He where two data set are plotted with the uncertainty intervals and b) Ar gases. The pressure was set to 666 mbar.

Consequently, it can be safely assumed that $T_{\mathrm{g}}$ from front observation corresponds to the plasma volume where the emitter number density is the highest and being located within the micro-cavity. In DC glow discharges, this plasma volume corresponds to the negative glow from which yields the strongest light intensity. $T_{\mathrm{g}}$ obtained from side observation is obviously related to the -small- plasma volume outside the cavity. Figure 12a) presents a comparison of $T_{\mathrm{g}}$ inside and outside the micro-cavity in pure He. Due to the delicate alignment to collect the light on the MHCD side, a second data set with a shaded area is added to the graph in order to highlight the repeatability of the results as well as to show the uncertainty range. A clear difference between both curves evidences a thermal gradient in the MHCD. $T_{\mathrm{g}}$ outside the cavity rises continuously while the temperature inside remains constant. For $I_{\mathrm{MHCD}}$ up to $130 \mu \mathrm{A}$ it can be observed that $T_{\mathrm{g}}$ inside and outside are similar whereas $T_{\mathrm{g}}$ continues to rise with an increase of $I_{\mathrm{MHCD}}$ to reach a temperature difference of about $50 \mathrm{~K}$. This fact 
is also observed in the case of the Ar discharge as shown in figure 12b). While $T_{\mathrm{g}}$ is much higher in the Ar than in the He discharge, it is interesting to mention that a temperature difference between inside and outside the micro-cavity is observed starting from $150 \mu \mathrm{A}$ for both gases. This may be due to a transition from the quasi-normal regime towards the abnormal regime. It is expected to be strongly dependent on the geometry and the pressure. Prior observations with close-up high-speed imaging revealed that the cathode cavity seems to be filled by the plasma volume which quickly leads to an increase of the current density.

The hotter temperature outside the cavity is attributed to two reasons related to the thermal conductivity of the gas and the materials. Indeed, at $350 \mathrm{~K} \mathrm{Si}$ has a thermal conductivity of $119 \mathrm{~W} /(\mathrm{mK})$ while $\mathrm{SiO}_{2}$ formed by thermal oxidation is at $1.6 \mathrm{~W} /(\mathrm{m} \mathrm{K})$ [52]. Consequently, the $\mathrm{SiO}_{2}$ layer acts as an efficient thermal insulation whereas Si has the role of a heat sink for the gas located within the cavity. This is particularly demonstrated in the case of He where $T_{\mathrm{g}}$ inside the cavity remains constant due to the efficient heat transfer into the wall by conduction mechanism enhanced by a high thermal conductivity of the He gas. Inversely, outside of the cavity -where no efficient conduction occurs- the convection dominates the heat transfer with a much lower efficiency. The cooling effect of the discharge gas within the cavity is particularly effective in He while in Ar the effect is not as significant, probably because of the much higher $T_{\mathrm{g}}$ of the discharge which subsequently leads to a fast decrease of the thermal conductivity of $\mathrm{Si}$ [52].

\section{6. $T_{\text {rot }}$ within and out of the cavity in $\mathrm{He}$}

To consolidate the results presented in the previous section, $T_{\text {rot }}$ is measured inside and outside the micro-cavity in the case of a discharge in He. The approach is the same as previously described, with $T_{\text {rot }}$ evaluated for $\mathrm{N}_{2}(\mathrm{C}-\mathrm{B})(0-2)$ and $\mathrm{N}_{2}(\mathrm{C}-\mathrm{B})(1-3)$ bands. The results are presented in figure 13. In the first place one focuses on $T_{\text {rot }}$

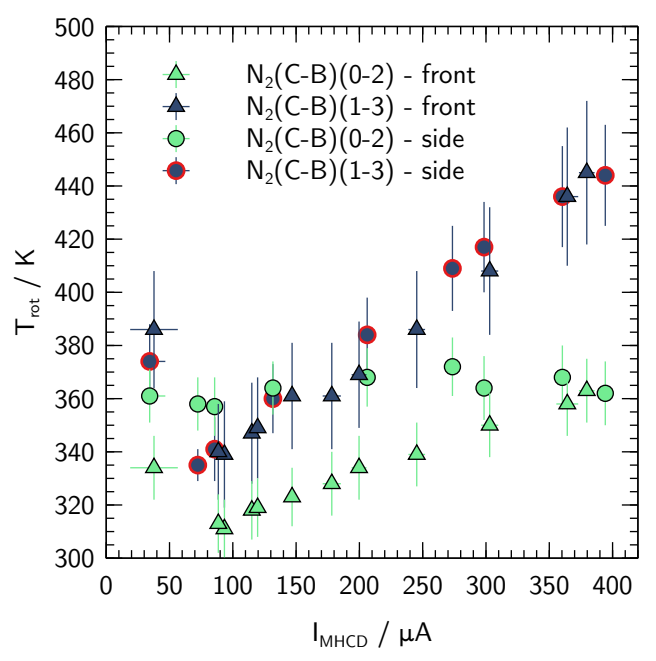

Figure 13. Comparison of $T_{\text {rot }}$ for two vibrational bands of $\mathrm{N}_{2}(\mathrm{C}-\mathrm{B})$ within (front) the MHCD cavity and outside (side) in He cases. The pressure was set to 666 mbar.

obtained for front observation. While absolute $T_{\text {rot }}$ values differ for each band, both 
curves described the same features. With the rise of the current, $T_{\text {rot }}$ increase linearly for both curves with a similar slope. It is expected that an extrapolation towards $I_{\mathrm{MHCD}}=0 \mu \mathrm{A}$ results in a slope-intercept which is close to the ambient temperature. Although for $I_{\mathrm{MHCD}}$ below $250 \mathrm{\mu A}, T_{\text {rot }}$ values might be considered in the same range, the discrepancies are enhanced with the rise of the current with approximately $100 \mathrm{~K}$ difference. A specific feature is observed for $I_{\mathrm{MHCD}}$ inferior to $50 \mu \mathrm{A}$ which corresponds to the limit of the self-pulsing mode. The latter corresponds to a transient regime which will be tackled in the next section. Interestingly, $T_{\text {rot }}$ is higher than in quasinormal regime leading to a "V"-shape of the $T_{\text {rot }}$ curves.

Observations performed on the side direction result in $T_{\text {rot }}$ values in the same range, although $T_{\text {rot }}$ of each band is not described by the same trends. While $T_{\text {rot }}$ of $\mathrm{N}_{2}(\mathrm{C}-$ B)(0-2) does not reveal any dependence of $I_{\mathrm{MHCD}}, T_{\text {rot }}$ of $\mathrm{N}_{2}(\mathrm{C}-\mathrm{B})(1-3)$ unexpectedly resembles the curve obtained from the front observation. Obviously, in these conditions $T_{\text {rot }}$ is not in equilibrium. In helium mixture $\tau_{\mathrm{C}} \approx 36.6 \mathrm{~ns}$ and $\tau_{\mathrm{R}-\mathrm{T}}$ is estimated to be in the range of $1 \mathrm{~ns}$ to $10 \mathrm{~ns}[39,51]$, which is -in this case- significantly faster than in pure $\mathrm{N}_{2}$ discharge. To understand the difference between $T_{\text {rot }}$ of each ro-vibrational band, vibrational quenching by He was investigated for $v=0$ and $v=1$ of the Cstate. According to [53], while $\tau_{\mathrm{C}}^{v=0} \approx 36.4 \mathrm{~ns}, \tau_{\mathrm{C}}^{v=1,2}$ could be reduced to $27 \mathrm{~ns}$ due to the quenching with He atoms. However this is reasonably longer than $\tau_{\mathrm{R}-\mathrm{T}}$. Two potential reasons have already been discussed to explain these discrepancies. In [10] the authors mentioned the vibrational quenching within the C-state such as,

$$
\mathrm{N}_{2}\left(\mathrm{C}, v_{1}^{\prime}\right)+\mathrm{He} \longrightarrow \mathrm{N}_{2}\left(\mathrm{C}, v_{2}^{\prime}, v_{2}^{\prime}<v_{1}^{\prime}\right)+\mathrm{He}
$$

as a possible cause of non-equilibrium rotational distribution all the more to justify the analysis of $T_{\text {rot }}$ of $\mathrm{N}_{2}(\mathrm{C}-\mathrm{B})(0-2)$ as a good estimation of $T_{\mathrm{g}}$ since no internal vibrational quenching is of concern. In all likelihood, it has already been addressed in several papers $[39,40,10]$ that many rate coefficients of the depopulation of the C-state are missing from the literature. The second reason might come from the population of $\mathrm{N}_{2}(\mathrm{C})$ from the $\mathrm{N}_{2}(\mathrm{~A})$ metastable state due to pooling reactions and direct electron excitation $[54,10]$.

$$
\mathrm{N}_{2}(\mathrm{~A})+\mathrm{N}_{2}(\mathrm{~A}) \longrightarrow \mathrm{N}_{2}(\mathrm{C})+\mathrm{N}_{2}(\mathrm{X}) \text {. }
$$

In this case, the relatively low number density of $\mathrm{N}_{2}(\mathrm{~A})$ is to be considered with regard to its long lifetime, especially in He discharge where the major quenching partner is $\mathrm{N}_{2}$ (A) itself. It cannot be excluded that in DC MHCD, the $\mathrm{N}_{2}(\mathrm{~A})$ concentration could be significant compared to discharge containing molecular oxygen or Ar [55].

Apart from the discussion on $T_{\text {rot }}$ deviations, temperature values are distributed in a well defined interval ranging from $310 \mathrm{~K}$ to $460 \mathrm{~K}$. The latter is in excellent agreement with previous measurements of $T_{\mathrm{g}}$ obtained by atomic line profile analysis. It is highlighted that both $T_{\text {rot }}$ and $T_{\mathrm{g}}$ show the same tendency regarding the thermal gradient of the discharge, i.e. the temperature is higher in the vicinity of the cavity opening than within the cavity. The latter fact supports the argumentation developed in the previous sections.

\subsection{Comparison between $T_{\mathrm{g}}$ and $T_{\text {rot }}$ in self-pulsing regime}

MHCDs have the ability to operate in continuous DC excitation and to switch under some particular conditions- in a fully transient mode so-called self-pulsing [56]. In this study, the self-pulsing regime has the advantage of varying permanently the electric excitation -as opposed to the continuous DC excitation- without adding an 
electric insulation layer to the actual design and using a AC power supply [57]. This oscillating regime is described theoretically and experimentally as an alternate of transient expansions of the plasma onto the cathode surface for typically microseconds before to confines itself to sustain the discharge $[56,58]$. The relaxation oscillation frequency ranges from a couple of $\mathrm{kHz}$ up to $\mathrm{MHz}$ [2] and are expected to depend strongly on the gas, the pressure and the reactor geometries. Typical self-pulsing $V_{\mathrm{MHCD}}$ and $I_{\mathrm{MHCD}}$ waveforms are shown in figure 14 . In the present conditions, the

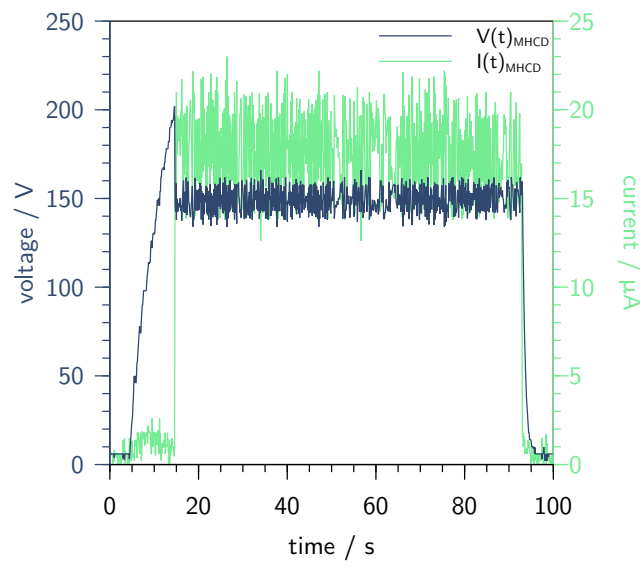

Figure 14. Typical voltage and current waveforms of a single MHCD reactor operated in self-pulsing regime in $\mathrm{He}$ at $666 \mathrm{mbar}$. The average current is $17 \pm 2 \mu \mathrm{A}$ for an average dissipated power of $2.5 \pm 0.5 \mathrm{~mW}$.

oscillation frequencies were estimated to range from $1 \mathrm{kHz}$ to $3 \mathrm{kHz}$ by means of fourier transform analysis. The electronic excitation and ionization mechanisms are expected to change due to these rapid fluctuations. This constitutes an opportunity to study $T_{\mathrm{g}}$ and $T_{\text {rot }}$ in these conditions.

The averaged current is set to $17 \pm 2 \mu \mathrm{A}$ to operate the MHCD far enough from the threshold current before to switch to the continuous quasi-normal regime. The observation are performed front-on to collect the light since the intensity is significantly lower. $T_{\mathrm{g}}$ and $T_{\text {rot }}$ are measured as described in the above sections. The results are shown in figure 15. Two data sets corresponding to two MHCD micro-reactors from different batches are used in this comparison since the self-pulsing regime can be also described as sustainable instabilities which may depend on tiny irregularities from cavity to cavity. Qualitatively, for both sets, $T_{\mathrm{g}}$ values are remarkably consistent and evidence the robustness of the line profile analysis to infer the neutral gas temperature. Regarding $T_{\text {rot }}$, the stability of the discharge and the reproducibility of the measurements are demonstrated which is quite substantial in the conditions of perpetual transient self oscillations. Quantitatively, a clear discrepancy is noticed between $T_{\mathrm{g}}$ and $T_{\text {rot }}$ while the latter is reasonably the same for the $\mathrm{N}_{2}(\mathrm{C}-\mathrm{B})(0-2)$ and $\mathrm{N}_{2}$ (C-B)(1-3) bands. This is observed for the first time in this study and suggests that the mechanisms governing the rotational population distributions of $\mathrm{N}_{2}(\mathrm{C})$ yield a better uniformity with regard to the vibrational levels. It is hypothesized that this can result from a significant fluctuation of the $\mathrm{N}_{2}(\mathrm{~A})$ metastable concentration in the self-pulsing regime which would reduce their probable contribution to populate $\mathrm{N}_{2}(\mathrm{C})$. Meanwhile, the difference between $T_{\mathrm{g}}$ and $T_{\text {rot }}$ implies to some degree that the 


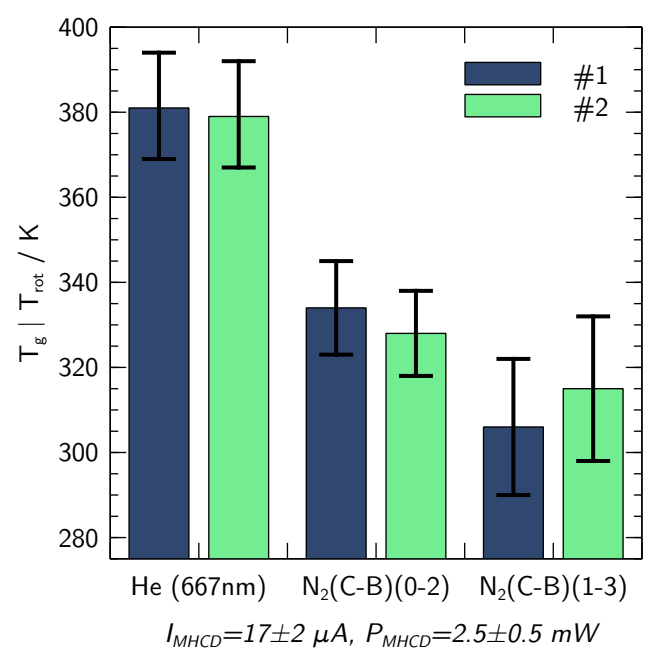

Figure 15. Comparison of $T_{\mathrm{g}}$ (after analysis of the He line profile at $667 \mathrm{~nm}$ ) and $T_{\text {rot }}$ of $\mathrm{N}_{2}(\mathrm{C}-\mathrm{B})$ for a single MHCD reactor operated in self-pulsing produced from two different batches labeled \#1 and \#2. The discharge operates in $\mathrm{He}$ at $666 \mathrm{mbar}, I_{\mathrm{MHCD}}=17 \pm 2 \mu \mathrm{A}$ and $\mathrm{P}_{\mathrm{MHCD}}=2.5 \pm 0.5 \mathrm{~mW}$. The uncertainties represents the $95 \%$ confidence interval.

rotational distributions deviate from the equilibrium.

Unexpectedly, for rather low $I_{\mathrm{MHCD}} T_{\mathrm{g}}$ is found higher than results shown in figure 8 corresponding to the quasi-normal regime with much higher current. However, higher temperatures were already observed with the exception of self-pulsing as discussed in section 4.6. An overestimation of $T_{\mathrm{g}}$ from the atomic line profile would mean that the Lorentzian contribution to the FWHM requires an additional broadening mechanism incorrectly attributed to the already considered effects. The extreme conditions of electric field imposed by the microscopic scale may suggest a potential broadening and shift of the line due to DC Stark effect. However in the present case, the latter is of no concern since the light was collected from the center of the cavity where the DC Stark effect is not present [59]. Thus it is argued that the analysis of the line profile provides the more realistic values of $T_{\mathrm{g}}$.

\subsection{Temperatures of $M H C D$ in the anodic cavity}

The case of MHCD with an anodic cavity is realized by switching the polarity of the surface electrode. The latter is supplied with a negative voltage whereas the bottom of the cavity remains grounded. This configuration leads to the generation of a discharge which expands onto the outer electrode acting as a cathode and yields a constant current density since the plasma is not limited by the cathode surface. A direct consequence is that typical values of $I_{\mathrm{MHCD}}$ are one order of magnitude higher compared to the prior configuration. Depending on the nature of the gas, the pressure and the geometry, the sheath at the cathode surface can shape the confinement of the plasma volume contained within the cavity [19].

To measure $T_{\mathrm{g}}$ and $T_{\text {rot }}$ in the plasma volume located within the cavity, the light is collected front-on. In this experiment, the discharge was ignited in He at two different pressures (267 mbar and $666 \mathrm{mbar}$ ). The results are show in figure 16. Note that the 


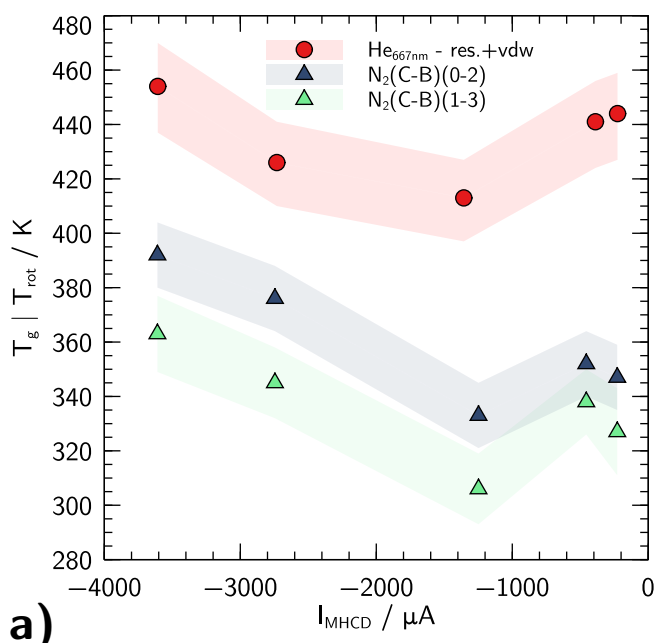

a)

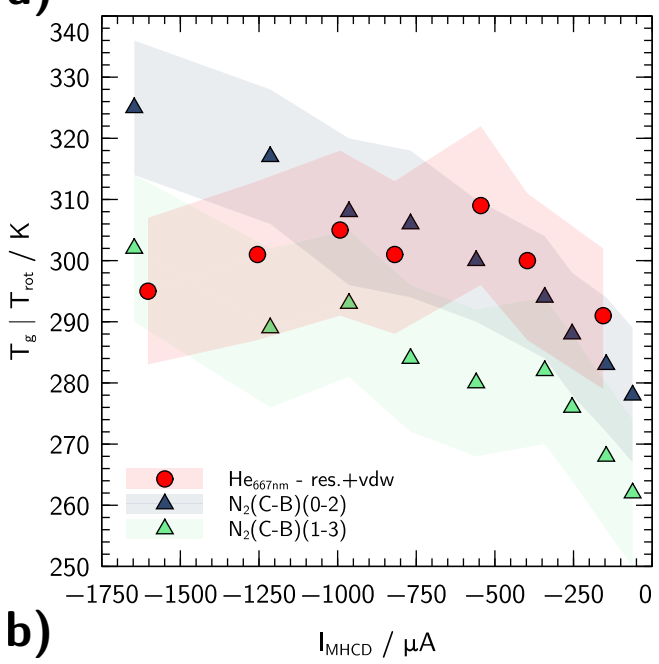

Figure 16. $T_{\mathrm{g}}$ and $T_{\text {rot }}$ inside the MHCD cavity in case of inverted polarity in $\mathrm{He}$ at a) 666 mbar and b) 267 mbar. Conventionally and in agreement with figure 1, $I_{\mathrm{MHCD}}$ is negative. Thus, in this specific case the bottom of the cavity has an anodic role.

current is conventionally negative to be consistent with the schematic of the MHCD in figure 1. At $666 \mathrm{mbar}$, values found for $T_{\mathrm{g}}$ and $T_{\text {rot }}$ are shown in figure 16a). While significant differences between $T_{\text {rot }}$ and $T_{\mathrm{g}}$ are observed, it is important to highlight that all the curves follow rigorously the same trend with the evolution of $I_{\mathrm{MHCD}}$. Intriguingly, the differential between the minimum and the maximum of each curve is about $50 \mathrm{~K}$ and evidencing a clear correlation between $T_{\text {rot }}$ and $T_{\mathrm{g}}$. The reason of the minimum while the current rises in absolute value is not clear though. One also notes that $T_{\text {rot }}$ of each $\mathrm{N}_{2}(\mathrm{C}-\mathrm{B})$ bands is not in complete agreement to consider the rotational population distributions in total equilibrium. This is argued with the absence of overlapping of the confident intervals.

By reducing the gas pressure down to $267 \mathrm{mbar}$, the discharge could be ignited while the cathode sheath occupies a larger volume in the vicinity of the cavity opening. The 
measured temperatures are shown in figure 16b). Remarkable agreements are found between $T_{\text {rot }}$ and $T_{\mathrm{g}}$. Due to the anodic cavity configuration of the MHCD operated at lower pressure, the current in absolute values ranges in a couple of hundreds $\mu \mathrm{A}$. Consequently, $T_{\mathrm{g}}$ is expected to stay very close to the temperature of the laboratory. Indeed, values of $T_{\mathrm{g}}$ found after analysis of the atomic line profile confirm the reliability of the method. For the first time the results of this study show $T_{\text {rot }}$ curves of both $\mathrm{N}_{2}(\mathrm{C})$ bands show convincing agreement with values obtained by line shape analysis. To explain this outcome, it is expected that the governing mechanisms responsible for the rotational population distributions allow the $\mathrm{N}_{2}(\mathrm{C})$ state to relax in equilibrium by R-T energy transfer. This relaxation seems to be more effective in a free-expanding plasma onto the cathode surface than in a confined plasma volume within a cathode cavity. Nevertheless, some values of $T_{\text {rot }}$ with their respective confidence interval are below the ambient temperature, which is particularly true for the $\mathrm{N}_{2}(\mathrm{C}-\mathrm{B})(1-3)$. While the reason have not been clearly identified, it corroborates with a relatively low neutral gas temperature of the discharge compared to the ambient temperature.

\section{Concluding remarks}

This study focuses on the neutral gas temperature $\left(T_{\mathrm{g}}\right)$ in DC MHCD elaborated on silicon substrate contributes to unveil new information on several aspects. It was successfully demonstrated that DC MHCD is able to operate in different gases, namely $\mathrm{He}, \mathrm{Ar}$ and $\mathrm{N}_{2}$ close to atmospheric pressure. To determine $T_{\mathrm{g}}$ within and in the vicinity of single micro-cavity, two independent optical emission spectroscopy approaches have been successfully investigated.

First, a thorough analysis of the line profile of resonant atomic transitions - Ar at $750.39 \mathrm{~nm}\left(2 \mathrm{p}_{1} \rightarrow 1 \mathrm{~s}_{2}\right)$ and He at $667.82 \mathrm{~nm}\left(3^{1} \mathrm{D} \rightarrow 2^{1} \mathrm{P}\right)-$ has been carried out to infer $T_{\mathrm{g}}$ values. The use of the reevaluated coefficient value $K(0,1)$ and the consideration of Van der Waals interactions on the broadening were newly introduced to room temperature plasmas.

A second method based on the evaluation of the rotational temperature of $\mathrm{N}_{2}$ bands is used. $T_{\text {rot }}$ of vibrational bands $\mathrm{N}_{2}(\mathrm{C}-\mathrm{B})(0-2)$ and $\mathrm{N}_{2}(\mathrm{C}-\mathrm{B})(1-3)$-present as trace in He discharge- are successfully determined by adjusting simulated spectra with a reduce set of parameters. A systematic $95 \%$ confident interval is computed to provide consistent uncertainties of $T_{\text {rot }}$ in order to support the validity of the method. In pure $\mathrm{N}_{2}$ discharge, $T_{\text {rot }}$ of $\mathrm{N}_{2}(\mathrm{C}-\mathrm{B})(2-4)$ was also investigated.

Consistent values of $T_{\mathrm{g}}$ were found in Ar discharge ranging from $460 \mathrm{~K}$ to $860 \mathrm{~K}$ depending on the current. Unfortunately, $T_{\text {rot }}$ of $\mathrm{N}_{2}$ cannot be considered in $\mathrm{Ar}$ discharge due to a quasi-resonant energy transfer with its metastable states. However, the used of the resonant line analysis enabled us to investigate that $T_{\mathrm{g}}$ does not change significantly with small admixture of $\mathrm{N}_{2}$ in the Ar discharge.

In He, $T_{\mathrm{g}}$ remains constant around $360 \mathrm{~K}$ and did not show a clear dependence of the current. The later is explained by a better thermal conductivity of He with the cavity material. Some discrepancies are reported between $T_{\text {rot }}$ values of different excited vibrational states recorded simultaneously while the curve can show the same trend. Although $T_{\mathrm{g}}$ determined by line profile analysis may differ from $T_{\text {rot }}$, both show values in a similar range between room temperature and $480 \mathrm{~K}$.

Measurements at the surface of the cavity opening revealed a gradient of $T_{\mathrm{g}}$ in $\mathrm{Ar}$ and He discharges. Interestingly, the temperature close to the cathode surface is lower than in the outer cavity expansion. In the case of $\mathrm{He}$, this was partially found in 
$T_{\text {rot }}$ values while clear discrepancies where observed between $\mathrm{N}_{2}(\mathrm{C}-\mathrm{B})(0-2)$ and $\mathrm{N}_{2}(\mathrm{C}-$ B)(1-3). According to $T_{\mathrm{g}}$ results, this suggests that the wall of the cavity acts as a heat sink to better dissipate the heat flux. Meanwhile, it is expected that the $\mathrm{SiO}_{2}$ layer thermally isolates the upper outer electrode.

The other aspect of this work dealt with the deviation of $T_{\text {rot }}$ values of different $\mathrm{N}_{2}$ bands in $\mathrm{He}$ and pure $\mathrm{N}_{2}$ discharges. DC MHCD in $\mathrm{N}_{2}$ shows $T_{\text {rot }}$ from room temperature up to $550 \mathrm{~K}$ according to $\mathrm{N}_{2}(\mathrm{C}-\mathrm{B})(0-2)$ and $\mathrm{N}_{2}(\mathrm{C}-\mathrm{B})(1-3) . \mathrm{N}_{2}(\mathrm{C}-\mathrm{B})(2-$ 4) shows $T_{\text {rot }}$ much lower without clear explanation. Discrepancies where also found between $T_{\text {rot }}$ of $\mathrm{N}_{2}(\mathrm{C}-\mathrm{B})(0-2)$ and $\mathrm{N}_{2}(\mathrm{C}-\mathrm{B})(1-3)$ for He discharge. Switching the DC MHCD from quasi-normal regime to self-pulsing regime and then to anodic cavity led to conditions where $T_{\text {rot }}$ are in agreement with $T_{\mathrm{g}}$. From this, it is hypothesized that competitive energy transfer mechanisms are affecting the ro-vibrational population distributions of $\mathrm{N}_{2}(\mathrm{C})$ states, in particular the vibrational quenching within the Cstate.

Further investigations should be performed in this direction, especially the measure of internal vibrational quenching in noble gases. While $T_{\text {rot }}$ may be a good estimation of the range values of $T_{\mathrm{g}}$, the present study demonstrate that detailed analysis of resonant atomic line profiles is of high interest. The latter is particularly true in a context where the neutral gas temperature must be known with a high relative accuracy like in environmental, in biological and in medical applications.

\section{Acknowledgments}

This research was partly funded by CNRS PEPS "Ingnerie Verte" $\mathrm{M}_{\mathrm{i}} \mathrm{C}_{\mathrm{a}} \mathrm{DEAU}$. SI acknowledges CNRS INSIS for the junior scientist starting grant. GS was supported by the MESTD of the Republic of Serbia, Project 171034. SvdG acknowledges the project founding DFG-SFB1316. The authors thank the Réseau Plasmas froids (CNRS) for providing the calibration lamp. Discussions with Prof. N. Sadeghi and

Prof. N. Semmar are gratefully acknowledged.

\section{References}

[1] Bruggeman P and Brandenburg R 2013 Journal of Physics D: Applied Physics 46 464001464001 ISSN 0022-3727 \r1361-6463

[2] Schoenbach K H, El-Habachi A, Shi W and Ciocca M 1997 Plasma Sources Science and Technology 6468 ISSN 0963-0252

[3] Schoenbach K H and Becker K 2016 The European Physical Journal D 70 29-29 ISSN 2015606181

[4] Sun P P, Cho J H, Park C, Park S and Eden J G 2012 IEEE Transactions on Plasma Science 40 2946-2950 ISSN 0093-3813

[5] Lu X, Laroussi M and Puech V 2012 Plasma Sources Science and Technology 21 034005-034005 ISSN 0963-0252

[6] Lu X and Ostrikov K K 2018 Applied Physics Reviews 5031102

[7] Boeuf J P, Yang L L and Pitchford L C 2013 Journal of Physics D: Applied Physics 46 015201015201

[8] Liang Y, Li Y, Sun K, Zhang Q, Li W, Zhu W, Zhang J and Fang J 2015 Plasma Processes and Polymers 12 1069-1074

[9] Becker K H, Schoenbach K H and Eden J G 2006 Journal of Physics D: Applied Physics 39 R55-R70 ISSN 0022-3727, 1361-6463

[10] Wang Q, Koleva I, Donnelly V M and Economou D J 2005 Journal of Physics D: Applied Physics 381690 ISSN 0022-3727

[11] Lazzaroni C, Chabert P, Rousseau A and Sadeghi N 2010 Journal of Physics D: Applied Physics 43124008 ISSN 0022-3727 
[12] Elkholy A, Nijdam S, van Veldhuizen E, Dam N, van Oijen J, Ebert U and de Goey L P H 2018 Plasma Sources Science and Technology 27055014 ISSN 0963-0252

[13] Belostotskiy S G, Ouk T, Donnelly V M, Economou D J and Sadeghi N 2010 Journal of Applied Physics 107053305 ISSN 0021-8979

[14] Majstorović G, Jovović J and Šišović N 2017 Contributions to Plasma Physics $57282-292$ ISSN 08631042

[15] Sismanoglu B N, Grigorov K G, Caetano R, Rezende M V and Hoyer Y D 2010 The European Physical Journal D 60 505-516 ISSN 1434-6079

[16] Penache C, Miclea M, Bräuning-Demian A, Hohn O, Schössler S, Jahnke T, Niemax K and Schmidt-Böcking H 2002 Plasma Sources Science and Technology 11476 ISSN 0963-0252

[17] Yubero C, Rodero A, Dimitrijevic M S, Gamero A and García M C 2017 Spectrochimica Acta Part B: Atomic Spectroscopy 129 14-20 ISSN 0584-8547

[18] Rodero A and García M C 2017 Journal of Quantitative Spectroscopy and Radiative Transfer 198 93-103 ISSN 0022-4073

[19] Michaud R, Felix V, Stolz A, Aubry O, Lefaucheux P, Dzikowski S, Schulz-von der Gathen V, Overzet L J and Dussart R 2018 Plasma Sources Science and Technology 27025005 ISSN 1361-6595

[20] Felix V, Lefaucheux P, Aubry O, Golda J, Schulz-von der Gathen V, Overzet L J and Dussart R 2016 Plasma Sources Science and Technology 25 025021-025021

[21] Konjević N 1999 Physics Reports 316 339-401 ISSN 0370-1573

[22] Belmonte T, Noël C, Gries T, Martin J and Henrion G 2015 Plasma Sources Science and Technology $24064003-064003$

[23] Laux C O, Spence T G, Kruger C H and Zare R N 2003 Plasma Sources Science and Technology 12125 ISSN 0963-0252

[24] Djurović S and Konjević N 2009 Plasma Sources Science and Technology 18035011 ISSN 09630252

[25] Lewis E 1980 Physics Reports 58 1-71 ISSN 03701573

[26] Kramida A, Ralchenko Y, Reader J and NIST ASD Team 2018 NIST Atomic Spectra Database Version 5.6, [Online], National Institute of Standards and Technology, Gaithersburg, MD.

[27] Belostotskiy S G, Khandelwal R, Wang Q, Donnelly V M, Economou D J and Sadeghi N 2008 Applied Physics Letters 92221507 ISSN 0003-6951

[28] Dufour T, Overzet L J, Dussart R, Pitchford L C, Sadeghi N, Lefaucheux P, Kulsreshath M and Ranson P 2010 The European Physical Journal D 60 565-574

[29] Sahal-Bréchot S, Dimitrijevic M S, Ben Nessib N and Moreau N 2019 STARK-B database http://stark-b.obspm.fr - Observatory of Paris, LERMA and Astronomical Observatory of Belgrade

[30] Sahal-Bréchot S, Dimitrijević M S and Nessib N B 2017 Open Astronomy 20 523-530

[31] Griem H R 1997 Principles of Plasma Spectroscopy (Cambridge Monographs on Plasma Physics no 2) (Cambridge, [Eng.] ; New York: Cambridge University Press) ISBN 978-0-521-45504-6

[32] Pipa A V, Ionikh Y Z, Chekishev V M, Dünnbier M and Reuter S 2015 Applied Physics Letters $106244104-244104$

[33] Yubero C, Dimitrijević M S, García M C and Calzada M D 2007 Spectrochimica Acta Part B: Atomic Spectroscopy 62 169-176 ISSN 0584-8547

[34] Konjević N, Lesage A, Fuhr J R and Wiese W L 2002 Journal of Physical and Chemical Reference Data 31 819-927 ISSN 0047-2689

[35] Ranson P and Chapelle J 1974 Journal of Quantitative Spectroscopy and Radiative Transfer 14 1-18 ISSN 0022-4073

[36] Miller T M 2017 Atomic and Molecular Polarizabilities CRC Handbook of Chemistry and Physics: A Ready-Reference Book of Chemical and Physical Data. ed Haynes W M, Lide D R and Bruno T J (CRC Press) pp 10-188 97th ed ISBN 978-1-4987-5429-3

[37] Thompson P, Cox D E and Hastings J B 1987 Journal of Applied Crystallography 20 79-83 ISSN 0021-8898

[38] Ida T, Ando M and Toraya H 2000 Journal of Applied Crystallography 33 1311-1316 ISSN 0021-8898

[39] Bruggeman P J, Sadeghi N, Schram D C and Linss V 2014 Plasma Sources Science and Technology 23023001 ISSN 0963-0252, 1361-6595

[40] Wang Q, Doll F, Donnelly V M, Economou D J, Sadeghi N and Franz G F 2007 Journal of Physics D: Applied Physics 404202 ISSN 0022-3727

[41] Herzberg G 1950 Molecular Spectra and Molecular Structure. Vol. 1: Spectra of Diatomic Molecules 2nd ed vol 1 (New York: D. Van Nostrand Reinhold, inc.)

[42] Kovàcs I 1969 Rotational structure in the spectra of diatomic molecules (London: Hilger) ISBN 
978-0-85274-142-9

[43] Roux F, Michaud F and Vervloet M 1993 Journal of Molecular Spectroscopy 158 270-277 ISSN 0022-2852

[44] Pearse R W B and Gaydon A G 1976 The Identification of Molecular Spectra (London: Chapman \& Hall) ISBN 978-94-009-5760-2 978-94-009-5758-9

[45] Taylor J R 1997 An Introduction to Error Analysis: The Study of Uncertainties in Physical Measurements 2nd ed (Sausalito, Calif: University Science Books) ISBN 978-0-935702-42-2 978-0-935702-75-0

[46] Allen C W 1976 Astrophysical Quantities 3rd ed (London : [Atlantic Highlands] N.J: Athelone Press ; [Distributor for] U.S.A. and Canada, Humanities Press) ISBN 978-0-485-11150-7

[47] Kulsreshath M K, Schwaederle L, Overzet L J, Lefaucheux P, Ladroue J, Tillocher T, Aubry O, Woytasik M, G Schelcher and Dussart R 2012 Journal of Physics D: Applied Physics 45 285202 ISSN 0022-3727

[48] Boeuf J P, Pitchford L C and Schoenbach K H 2005 Applied Physics Letters 86071501 ISSN 00036951

[49] Huber M L and Harvey A H 2017 Thermal conductivity of gases CRC Handbook of Chemistry and Physics: A Ready-Reference Book of Chemical and Physical Data. ed Haynes W M, Lide D R and Bruno T J (CRC Press) pp 6-252 97th ed ISBN 978-1-4987-5429-3

[50] Nguyen T D and Sadeghi N 1983 Chemical Physics 79 41-55 ISSN 0301-0104

[51] Dilecce G, Ambrico P F and De Benedictis S 2007 Chemical Physics Letters 444 39-43 ISSN 0009-2614

[52] Bradley P E and Radebaugh R 2017 Properties of selected materials at cryogenic temperatures CRC Handbook of Chemistry and Physics: A Ready-Reference Book of Chemical and Physical Data. ed Haynes W M, Lide D R and Bruno T J (CRC Press) pp 12-204 97th ed ISBN 9781-4987-5429-3

[53] Gat E, Gherardi N, Lemoing S, Massines F and Ricard A 1999 Chemical Physics Letters 306 263-268 ISSN 0009-2614

[54] Bibinov N K, Fateev A A and Wiesemann K 2001 Journal of Physics D: Applied Physics 34 1819 ISSN 0022-3727

[55] Iseni S, Bruggeman P J, Weltmann K D and Reuter S 2016 Applied Physics Letters 108184101 184101

[56] Chabert P, Lazzaroni C and Rousseau A 2010 Journal of Applied Physics 108113307 ISSN 0021-8979

[57] Wollny A, Hemke T, Gebhardt M, Peter Brinkmann R, Boettner H, Winter J, Schulz-von der Gathen V, Xiong Z, Kushner M J and Mussenbrock T 2011 Applied Physics Letters 99 141504-141504

[58] Hsu D D and Graves D B 2003 Journal of Physics D: Applied Physics 36 2898-2907 ISSN 0022-3727, 1361-6463

[59] Jovović J and Konjević N 2014 The European Physical Journal D 6860 ISSN 1434-6079 